\title{
Evaluation of Aqua-Ammonia Chiller Technologies and Field Site Installation
}

\author{
September 2007 \\ Prepared by \\ A. Zaltash, Ph.D. \\ Research Staff \\ Cooling, Heating and Power (CHP) Group \\ Engineering Science and Technology Division \\ Oak Ridge National Laboratory \\ Oak Ridge, Tennessee 37831 \\ for \\ Bruce Caldwell \\ NFESC Code 223 \\ Port Hueneme, California 93043 \\ (805) 982-3520 \\ bruce.a.caldwell@navy.mil \\ Department of Energy (DOE) Proposal Number \# 2307-S725-A1 \\ Prepared under DOE Contract \# DE-AC05-00OR22725 \\ between \\ Department of Energy Oak Ridge Operations Office \\ and \\ UT-Battelle, LLC
}





\section{Evaluation of Aqua-Ammonia Chiller Technologies and Field Site Installation}

\section{Contents}

Executive Summary

1. Abstract

2. About the Technology

3. Technology Evaluation

4. Selection and Evaluation of Sites for Chiller Installation and Field Testing

4.1 Naval Surface Warfare Center Corona, Norco, California

4.2 Pearl Harbor Naval Station, Hawaii

4.3 Naval and Marine Corps Reserve Center, Knoxville, Tennessee

4.4 Naval Amphibious Base, Little Creek, Norfolk, Virginia

4.5 Oak Ridge National Laboratory, Oak Ridge, Tennessee

4.6 Selected Sites

5. Control Strategies

6. Technology Performance
6.1 Data Collection
6.2 Laboratory Performance
6.3 Field Experience, NSWC Corona
6.4 Field Experience, ORNL
6.5 Field Experience, NAB Little Creek

7. Primary Fuel Utilization and Peak Demand Savings

8. Conclusions

9. Acknowledgments

10. Bibliography 



\section{Executive Summary}

During cooling seasons, air-conditioning is the single largest use of electricity in both residential and commercial buildings and has the largest impact on peak electricity demand. Improved airconditioning technology would have by far the greatest potential for impact on the electric industry of any technology that uses electricity. Absorption chillers can provide overall peak load reduction and electric grid relief for summer peak demand. These chillers provide cooling to buildings by using thermal energy such as natural gas, steam, waste heat, and solar energy. Instead of mechanically compressing a gas (as occurs with an electricity-driven vaporcompression refrigeration cycle), absorption cooling relies on a thermochemical compressor. Absorption chillers can change a building's thermal and electric profile by shifting cooling from an electric load to a thermal load. This shift can be very important for facilities with time-of-day electrical rates, high cooling season rates, and high -demand charges. Some facilities with highdemand charges might find it economical to install hybrid chiller plants with both electrical and absorption chillers. Such a move would allow the building energy managers to take advantage of fuel diversity, using absorption chillers when electric rates and demand charges are high and electric chillers when electric rates and demand charges are low.

Lithium bromide-water systems are used for larger tonnages in process applications. Ammoniawater systems are more common for small tonnages and for lower-temperature applications; they can achieve temperatures as low as $-40^{\circ} \mathrm{F}\left(-40^{\circ} \mathrm{C}\right)$. Ammonia-water systems are usually aircooled, whereas lithium bromide-water systems require condenser water-cooling, usually from a cooling tower. In either cycle, electric energy is needed only for pumps, fans, and controls.

Absorption chillers can be direct-fired or indirect-fired, and they can be single-effect or doubleeffect. Natural gas is an attractive primary fuel for direct-fired machines. With gas firing, emissions are low and can be further reduced by the application of low-nitrogen oxide emission $\left(\mathrm{NO}_{\mathrm{x}}\right)$ burners. Double-effect absorption machines recycle some of the internal heat to provide part of the energy required in the generator to create the high-pressure refrigerant vapor, making the cycle more energy-efficient. Absorption cooling equipment has very few moving parts and usually has a long service life.

Important improvements in absorption equipment in the last 10 years have included improved heat exchange materials, more reliable pumps and motors, and controls that permit precise process management.

The Naval Facilities Engineering Service Center (NFESC) has sponsored Oak Ridge National Laboratory (ORNL) to review, select, and evaluate advanced gas-fired 5-ton aqua-ammonia chiller technologies. Chillers with coefficient of performance (COP) values of 0.67 or better at Air-conditioning and Refrigeration Institute (ARI) $95^{\circ} \mathrm{F}$ outdoor rating conditions, with active refrigerant flow control and a variable-speed condenser fan, were selected for laboratory evaluation in a controlled environment at the ORNL Thermally-Activated Heat Pump (TAHP) environmental chambers. From three potential manufacturers only one, Ambian, met our COP goal and our schedule.

Two Ambian pre-commercial chillers were evaluated. The chillers operated well at the ARI steady-state conditions over a wide range of ambient conditions by effectively using control strategies such as a variable-speed condenser fan, a modulating burner, and a thermal expansion valve (TXV) for active refrigerant flow control. The capacity of these units was found to be 
approximately 56,500 Btu/h (4.7 RT) with a COP of 0.66 at the ARI $95^{\circ} \mathrm{F}$ condition. Within the accuracy range of the instrumentation, these results indicate that the Ambian units meet the desired performance levels for both capacity and COP. In addition, the units were operated at the ARI “C” cooling condition ( $82^{\circ} \mathrm{F}$ ambient temperature, steady state, dry coil). At this condition, the unit was using its modulating burner capability to optimize its performance by maintaining the chilled water temperature at around $45^{\circ} \mathrm{F}$. The COP and capacity were found to be 0.72 and 48,000 Btu/h (4.0 RT), respectively. When the unit was forced to operate at a low firing rate, then it operated with a COP of 0.84 and a capacity of $42,000 \mathrm{Btu} / \mathrm{h}(3.5 \mathrm{RT})$. The CO concentration was found to be 8 parts per million based on volume (ppmv) and the $\mathrm{NO}_{\mathrm{x}}$ concentration less than 13 ppmv.

Ambian pre-commercial units were selected for installation and field testing at three federal facilities. NFESC worked with ORNL to select these sites. Site selection criteria included building type, load, available back-up (redundant) air-conditioning systems, ease of installation of the chiller and hydronic loop, project economics, and proximity to and interest of site personnel.

Two selected sites (ORNL and Naval Surface Warfare Center [NSWC] Corona) had a single chiller unit each, and the third site (Naval Amphibious Base [NAB] Little Creek) had two 5-ton chillers linked together to provide 10 tons of cooling. A chiller link controller developed under this project was evaluated in the field test at Little Creek. Since these units are pre-commercial units, some reliability/dependability issues were expected, so all three facilities were equipped with back-up cooling systems.

At two of the three sites (NSWC and NAB), the expected load in the buildings was not large enough to require all the cooling capacity of these chillers. This resulted in short run times with concomitant cycling losses and lower-than-expected performance. However, the third field test at ORNL had a relatively good match between building load and unit capacity and showed good performance with a COP of as high as 0.74 and capacity as high as 55,040 Btu/h (4.6 RT). As expected, some reliability and dependability issues were experienced with some of the components—noisy TXVs, leaks from compression fittings/valves, and faulty readings from ambient air temperature sensor. Additionally, minor changes were made to the control scheme/strategies and to the sequencing to optimize the performance of these chillers in the field. These issues have been identified and should be mitigated on subsequent units. 


\section{Evaluation of Aqua-Ammonia Chiller Technologies and Field Site Installation}

\section{Abstract}

The Naval Facilities Engineering Service Center (NFESC) has sponsored Oak Ridge National Laboratory (ORNL) to review, select, and evaluate advanced, gas-fired, 5-ton, aqua-ammonia, chiller technologies. The selection criteria was that units have COP values of 0.67 or better at Air-conditioning and Refrigeration Institute (ARI) $95^{\circ} \mathrm{F}$ outdoor rating conditions, an active refrigerant flow control, and a variable-speed condenser fan. These features are expected to allow these units to operate at higher ambient temperatures (up to the maximum operating temperature of $110^{\circ} \mathrm{F}$ ) with minimal degradation in performance. ORNL evaluated three potential manufacturers of advanced, gas-fired, 5-ton, aqua-ammonia chillers-Robur, Ambian, and Cooling Technologies. Unfortunately, Robur did not meet the COP requirements and Cooling Technologies could not deliver a unit to be tested at the U.S. Department of Energy (DOE)-ORNL environmental chamber testing facility for thermally activated heat pumps. This eliminated these two technologies from further consideration, leaving only the Ambian chillers for evaluation.

Two Ambian chillers were evaluated at the DOE-ORNL test facility. Overall these chillers operated well over a wide range of ambient conditions with minimal degradation in performance due to several control strategies used such as a variable speed condenser fan, a modulating burner, and active refrigerant flow control. These Ambian pre-commercial units were selected for installation and field testing at three federal facilities. NFESC worked with ORNL to assist with the site selection for installation and evaluation of these chillers. Two sites (ORNL and Naval Surface Warfare Center [NSWC] Corona) had a single chiller unit installed; and at one site (Naval Amphibious Base [NAB] Little Creek), two 5-ton chillers linked together were installed to provide 10 tons of cooling. A chiller link controller developed under this project was evaluated in the field test at Little Creek.

\section{About the Technology}

Heating and air conditioning consume almost half the energy used in buildings in the United States. Air conditioning is the chief cause of peak electricity demand and uses halogenated refrigerants linked to environmental ozone depletion and global warming. An absorption chiller does not use a compressor or environmentally damaging refrigerants. Instead, natural refrigerant vapor is absorbed in a solution, which is then pumped to a high-pressure generator chamber where it is heated and the refrigerant boils off as a high-pressure vapor. (The remainder of the cycle is essentially the same as in a conventional system.) A natural gas burner supplies the heat to the generator. The advanced aqua-ammonia absorption unit, which uses ammonia as the refrigerant, has a heat-exchange loop between the generator and absorber that increases the cooling efficiency by recycling the heat released in the absorber when the refrigerant mixes with water.

A major environmental advantage of the advanced aqua-ammonia cycle is that it uses ammonia and water rather than long-lived, environmentally persistent refrigerants. In addition, because aqua-ammonia units consume less power than standard units, they could substantially reduce 
carbon emissions from the burning of fossil fuels in power plants and reduce seasonal peak demands on the electricity system.

\section{Technology Evaluation}

ORNL evaluated three potential manufacturers of advanced, gas-fired, 5-ton, aqua-ammonia, pre-commercial chillers-Robur, Ambian, and Cooling Technologies. As documented in the Task 1 report entitled "Selection and Evaluation of Aqua-Ammonia Technologies," Ambian and Cooling Technologies met the initial criteria of COP values of 0.67 or better at ARI $95^{\circ} \mathrm{F}$ outdoor rating conditions and having an active refrigerant flow control and variable-speed condenser fan. These features are expected to allow these units to operate at higher ambient temperatures (up to the maximum operating temperature of $110^{\circ} \mathrm{F}$ ) with minimal degradation in performance. Unfortunately, Cooling Technologies could not deliver a unit to be tested at the DOE-ORNL environmental chambers and was eliminated from further consideration, leaving only the Ambian pre-commercial chillers for further evaluation.

Two Ambian chillers were evaluated at the DOE-ORNL environmental chambers (Task 1 Report). Overall these chillers operated well over a wide range of ambient conditions with minimal degradation in performance as a result of several control strategies used, such as the variable-speed condenser fan, modulating burner, and active refrigerant flow control. The recommendation after evaluation in the environmental chambers was to move forward with the installation of the Ambian units in the field.

\section{Selection and Evaluation of Sites for Chiller Installation and Field Testing}

NFESC worked with ORNL to assist with the selection and evaluation of potential sites for the chiller installations. Five federal sites were evaluated:

- NSWC Corona, Norco, California

- Pearl Harbor Naval Station, Hawaii

- Naval and Marine Corps Reserve Center, Knoxville, Tennessee

- NAB Little Creek, Norfolk, Virginia

- ORNL, Oak Ridge, Tennessee

Site selection criteria included building type, load, available back-up (redundant) air conditioning systems, ease of installation of the chiller and hydronic loop, project economics, and proximity to and interest of site personnel.

\subsection{Naval Surface Warfare Center Corona, Norco, California}

NSWC Corona was visited by NFESC on March 2 - 3, 2004, for review of Building C539, Corona's candidate for installation of the advanced chiller. Building C539 is a soundly constructed, single-story, stucco building with a pitched roof, drop ceiling, and four core rooms.

Municipal water, natural gas (pressure of $~ 10$ psig), electricity, and central plant heating hot water (pressure of $\sim 40$ psig and temperature of $\sim 190^{\circ} \mathrm{F}$ ) are all available. No sub-metering of any kind was found during the site visit. 
NSWC Corona is interested in installation of a completely new cooling and heating system to serve Room 1 of Building C539 (Figure 1) because the existing HVAC system is undersized for cooling and provides almost no heating. The room was originally designed as a printing shop, but Corona now plans to use Room 1 for training, with seating for 30 students and 1 computer per 5 people. Room 1 is $1600 \mathrm{ft}^{2}$ with an exposed ceiling-hung air handler with a 3/4-hp motor, direct expansion (DX) coil, and room thermostat. The air handler is in fair to good condition, with no room for inserting another coil between the intake filters, DX coil, and fan. A 5-ton condenser unit is on the ground just outside the room. The only source of heating is a small fanpowered unit heater that hangs from the ceiling and uses central plant heating hot water. The heater is manually switched on from the electric room.
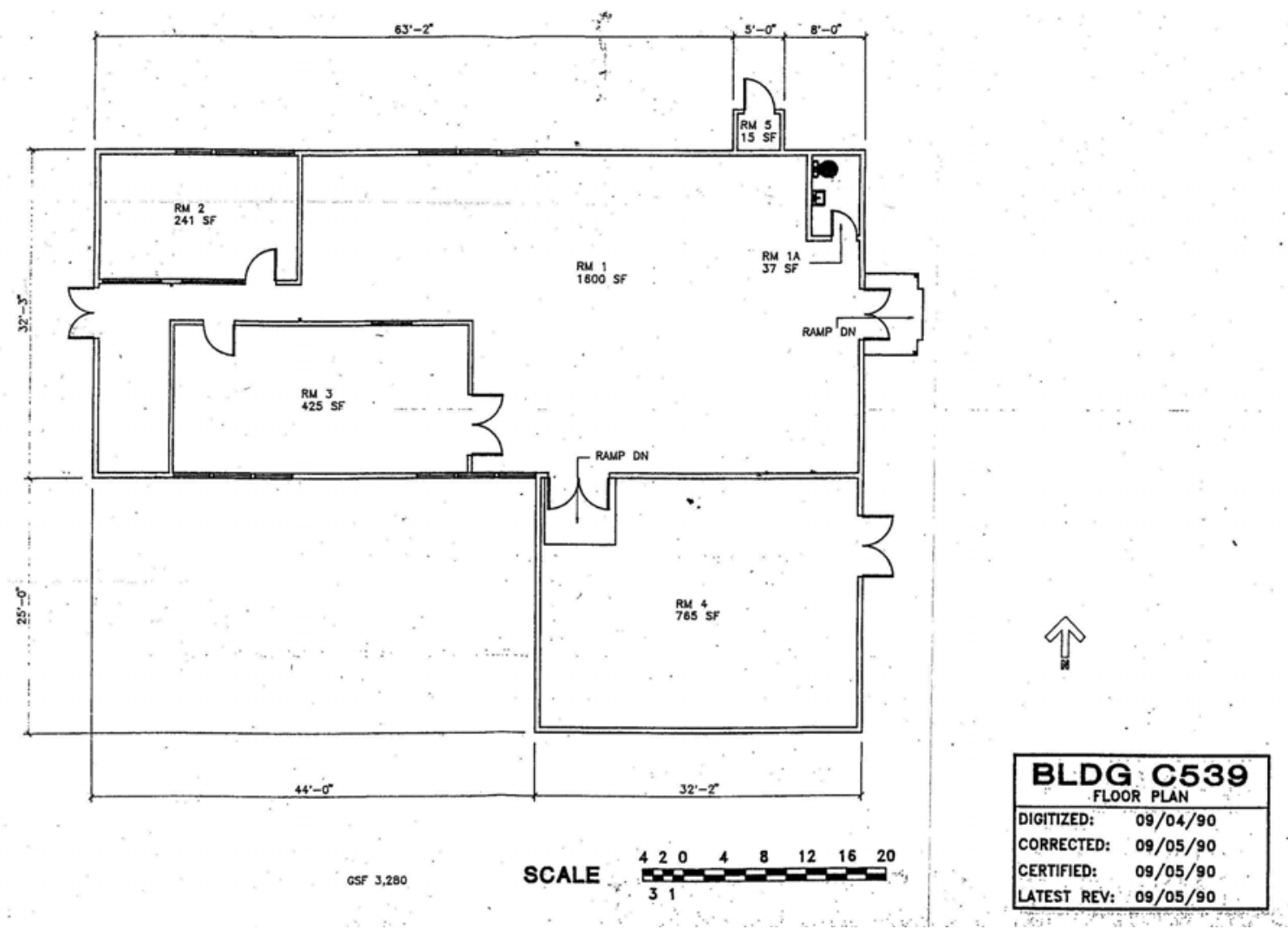

Figure 1. Floor plan for Building C539, NSWC Corona

\subsection{Pearl Harbor Naval Station, Hawaii}

Pearl Harbor Naval Station was visited by NFESC on March 29-April 2, 2004. NFESC located two prospective sites for installation of a 5-ton chiller: (1) in Building 161 of Bloch Arena, which is a ticket office for recreational events for military families, and (2) in Building 1623 (Arizona Hall), which is the reception office for the bachelor enlisted quarters (BEQ).

The area in Building 161 to be cooled is $596 \mathrm{ft}^{2}$ with no existing ductwork. Above a 9-ft drop ceiling is a slanted roof with ample space for flexible duct, but perhaps no room for an indoor fan unit. There is one ductless condensing unit outside that serves two fan units in the space. The space currently has 4 tons of cooling, which is not adequate to keep the staff comfortable in hot 
weather, and would be better served by a 5-ton unit. Finding a suitable lay-down location might be difficult, particularly if the existing unit is kept as a backup cooling system.

The area to be cooled in Building 1623, the BEQ reception office, is $325 \mathrm{ft}^{2}$ with a 9.5-ft drop ceiling. There is no existing ductwork. The roof slopes down to approximately $4 \mathrm{ft}$ at the south side. There is plenty of room for a fan coil and ductwork. There are two ductless condensing units on the hallway roof that serve three indoor units. The space currently has 3.25 tons of cooling but would be better served by a 5-ton unit. Three possible lay-down locations were evaluated: (1) next to the units currently serving the building just to the northwest of the reception office; (2) on the roof over the front desk area and supervisor/building manager's office northeast of the reception office, where there is easy access to the attic space for piping; and (3) In the grass to the east of area \#2.

This site was not recommended for installation of this pre-commercial unit because of potential problems with transportation and providing adequate site support. However, this site would be a good candidate once this technology becomes more mature and more reliable.

\subsection{Naval and Marine Corps Reserve Center, Knoxville, Tennessee}

The Naval and Marine Corps Reserve Center was visited by ORNL on July 20, 2004. Building 2 is currently unoccupied and expected to remain so and has no significant internal loads. Before the construction of a new structure, Building 2 was the Reserve Center, containing offices, classrooms, storage space, a weight room, and a damage control training facility. The building is rectangular with dimensions of $40 \times 100 \mathrm{ft}$, giving a total floor area of $4000 \mathrm{ft}^{2}$. The height to the roof eaves is $14 \mathrm{ft}$, and peak roof height is $20 \mathrm{ft} 8 \mathrm{in}$. The roof has a 4:12 slope on the short dimension. Less than half the area has drop ceilings.

ORNL's contact at the reserve center described mold and mildew problems as well as general mustiness in the building. The walk-through confirmed this and showed warped, dislodged, and stained ceiling panels, dangling air diffusers, and displaced insulation, which is consistent with lack of use and maintenance.

Adequate natural gas and electricity service remain available at the site. However, the natural gas supply line is at the southeast corner of building, while the existing heat pump (and, probably, the proposed absorption chiller, if implemented) is near the northwest corner of the building.

The contact confirmed that he had discussed the potential installation with the center commander. Any operation of new equipment in Building 2 would result in additional operating cost to the center, which is not acceptable to the commander. Based on the survey and comments received, this building does not seem to be a good candidate for the 5-ton field installation.

\subsection{Naval Amphibious Base, Little Creek, Norfolk, Virginia}

NAB Little Creek was visited by ORNL on March 8, 2005. The kitchen and laundry area in Building 3364 (Figure 2) was evaluated for installation of two 5-ton chillers linked together to provide up to 10 tons of cooling. Building 3364 has a single story and is soundly constructed of 


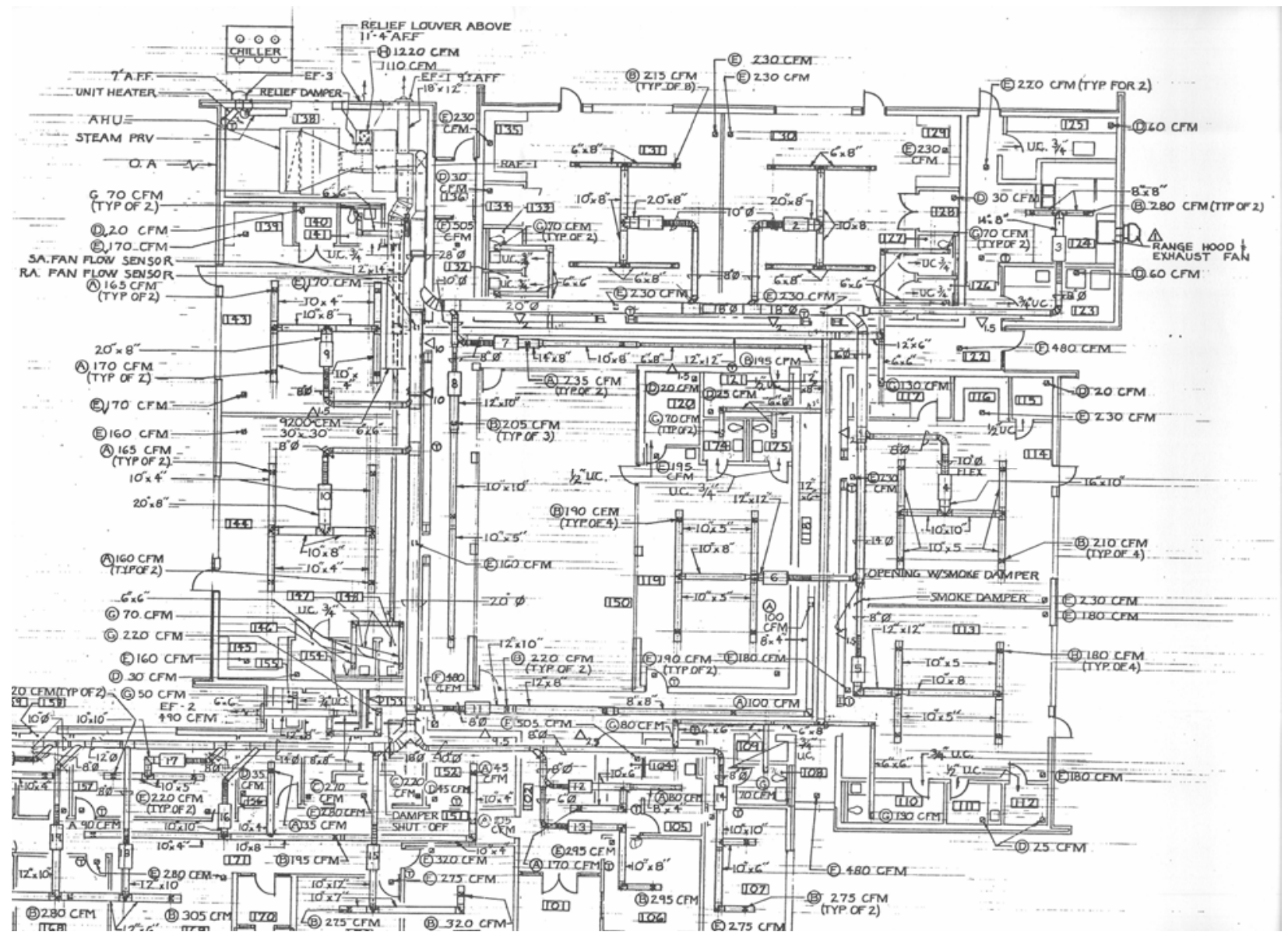

Figure 2. Floor plan of Building 3364, NAB Little Creek

brick. The building has a drop ceiling and a flat roof. Little Creek reports that the existing HVAC system is undersized and does not provide adequate cooling for the kitchen and laundry area.

The kitchen is approximately $12 \times 12 \mathrm{ft}$ with two freezers, two refrigerators, and a range for cooking. The laundry is approximately $9 \times 5 \mathrm{ft}$ with gas-fired water heater, washer, and dryer. Natural gas and electricity (208 VAC source) are all available. The kitchen is believed to require less than 5 tons of chiller capacity. A fan coil unit can be placed in the return area above the drop ceiling to provide an additional load to the chiller link and make up the rest of the 10 tons. Based on the survey, this building was recommended for the field installation of two linked 5-ton chillers together with the chiller link control developed under Task 3 of this project.

\subsection{Oak Ridge National Laboratory, Oak Ridge, Tennessee}

The Building 3144 Annex, on the north end of the ORNL campus, has been used for Research and Development (R\&D) projects on building equipment technologies since 1984. Figure 3 shows the floor plan of this building, which contains ORNL's environmental chambers for testing building equipment. The environmental chambers are two-room psychometric test stands 


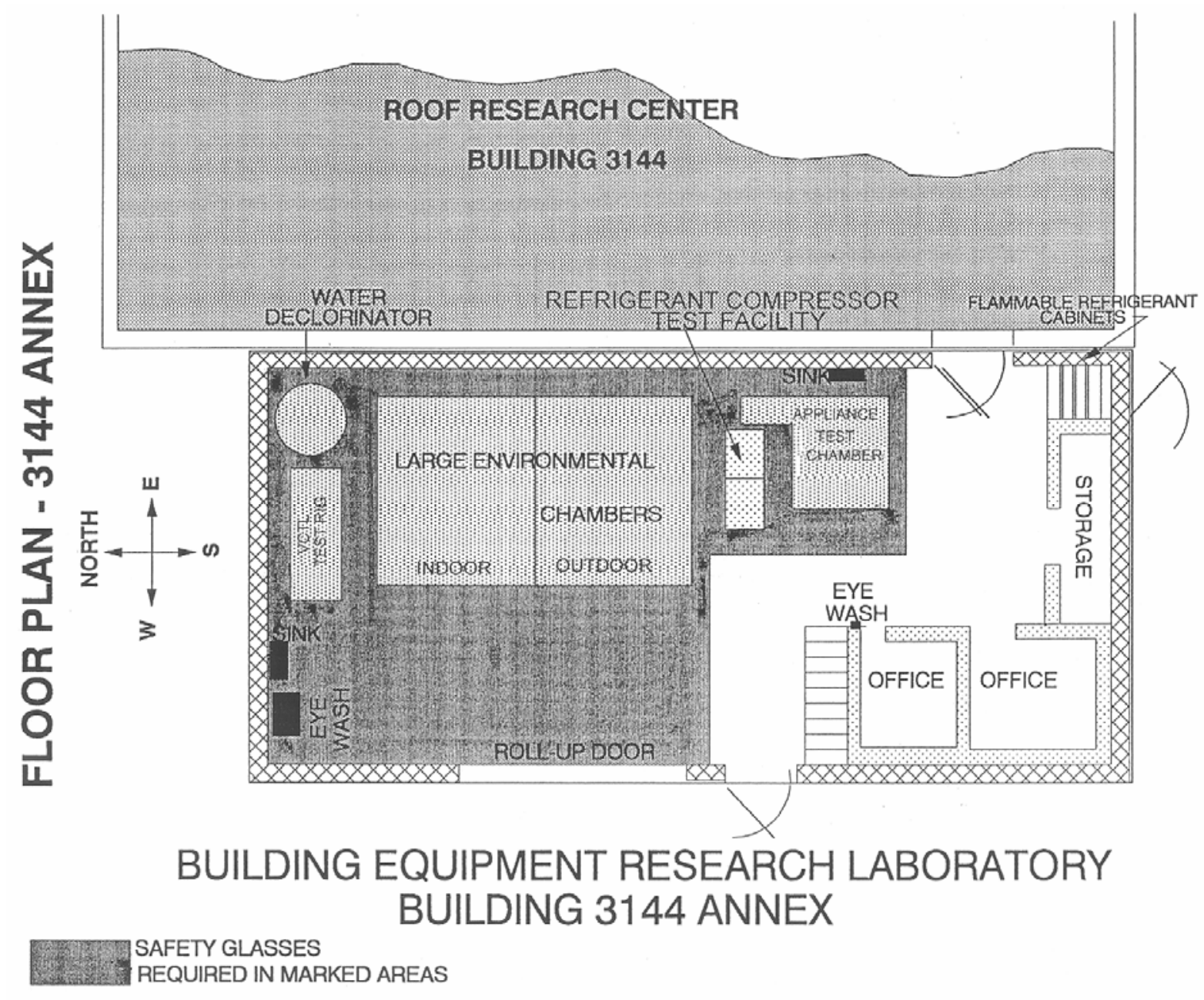

Figure 3. Floor plan of Building 3144A, ORNL

that feature both natural gas and electric utilities to support testing of TAHPs, electric vapor compression heat pumps, refrigerators, desiccant systems, and fully hydronic and small distributed generation/combined heat and power systems. The larger room is $15 \times 18 \mathrm{ft}$ and the smaller room is $15 \times 12 \mathrm{ft}$. The refrigeration system of these chambers can support 20 tons of load at an ambient temperature of $95^{\circ} \mathrm{F}$. The refrigeration plant can hold the temperature of the conditioned space at $-20^{\circ} \mathrm{F}$ while supporting a 3-ton load with $300 \mathrm{cfm}$ of laboratory make-up air injected into the system. Relative humidity can be controlled in each room over a 50-90\% range. This is achieved with a refrigerant plant of three 30-hp compressors, steam injection, and desiccant unit. In addition to these chambers, there is a smaller chamber for testing appliances such as heat pump water heaters and refrigerators.

Building 3144 Annex (3144A) is a soundly constructed, metal, single-story, high bay, with a flat roof, concrete floor, two rooms, and a storage room. This building is approximately 20 years old with dimensions of $80 \mathrm{ft} \mathrm{L} \times 40 \mathrm{ft} \mathrm{W} \times 19.5 \mathrm{ft} \mathrm{H}$. Potable water, natural gas, electricity, and steam are all available. The storage room is $8 \times 17 \mathrm{ft}\left(136 \mathrm{ft}^{2}\right)$. This building has three outside walls and one interior wall with two doors. It has one metal rolling door in the west exterior wall with dimensions of $17 \mathrm{ft} \mathrm{W} \times 19 \mathrm{ft} \mathrm{H}$. The existing HVAC system is undersized for cooling 
during hot summer days and when the chambers are operating (with steam injection and heat load from the rolling door). A 5-ton absorption chiller would be a good match for the load of this building during hot and humid summer days.

The high bay area is $2776 \mathrm{ft}^{2}$ with a mezzanine of $424 \mathrm{ft}^{2}$. It has two insulated single metal doors with single-pane glass $(2 \times 3 \mathrm{ft})$ and five windows (not glazed and not insulated). The air handler is in fair to good condition with 10-ton cooling capacity. The bay area is occasionally occupied by two persons and has two computers, one printer, flue gas analyzer, dechlorinator, set-up for heat pump water heater testing, and the three chambers mentioned previously. Heating is provided by steam coil in the air handler.

Room 1 is $144 \mathrm{ft}^{2}$ and has a 1-ton cooling/heating wall unit in good condition. This room, occupied by one person, has one $6 \times 4 \mathrm{ft}$ window, two computers, and one printer. Room 2 is the control room for the environmental chambers and is occasionally occupied by two persons with two computers and two printers. Room 2 is $144 \mathrm{ft}^{2}$ with one $6 \times 4 \mathrm{ft}$ window, and has a 3-ton cooling unit in good condition on the concrete pad just outside the room on the west.

\subsection{Selected Sites}

Based on the survey, three sites were selected for chiller installations (Task 2 report). ORNL and NSWC Corona were each selected for installation of a single 5-ton unit. NAB Little Creek was selected for installation of two 5-ton chillers linked together to provide 10 tons of cooling.

At Corona, the advanced 5-ton chiller was installed to serve Room 1 of Building C539. The cooling is achieved primarily by the new chiller, but Building C539 also has a 5-ton conventional vapor compression system for redundancy. Both chillers use a single air handling unit custom made for outdoor use, which will also have a hot water coil for heating Room 1 . The installation of this set-up was completed in April 2005, and the commissioning and startup were initiated in June 2005 (Figure 4).

The kitchen and laundry area of Building 3364 at the Little Creek site was selected for installation of two 5-ton chillers together with a chiller link controller developed under this project. The cooling in these two areas is achieved primarily by the chiller link using two air handling units. The existing cooling system is used as the back-up with the chiller link. The installation of this setup was completed in November 2006, and commissioning and startup were initiated in April 2007 (Figure 5).

The fourth 5-ton absorption chiller was installed at the ORNL Building 3144A site in May 2006, and commissioning was initiated in June 2006 (Figure 6). The previously existing cooling system is used as a (redundant) back-up to the new absorption chiller, which has been installed on the northwest corner of the building with the air handler just inside the building. Automated logic control and Web control are used for remote monitoring of the data and making the data available on the password protected web site. 


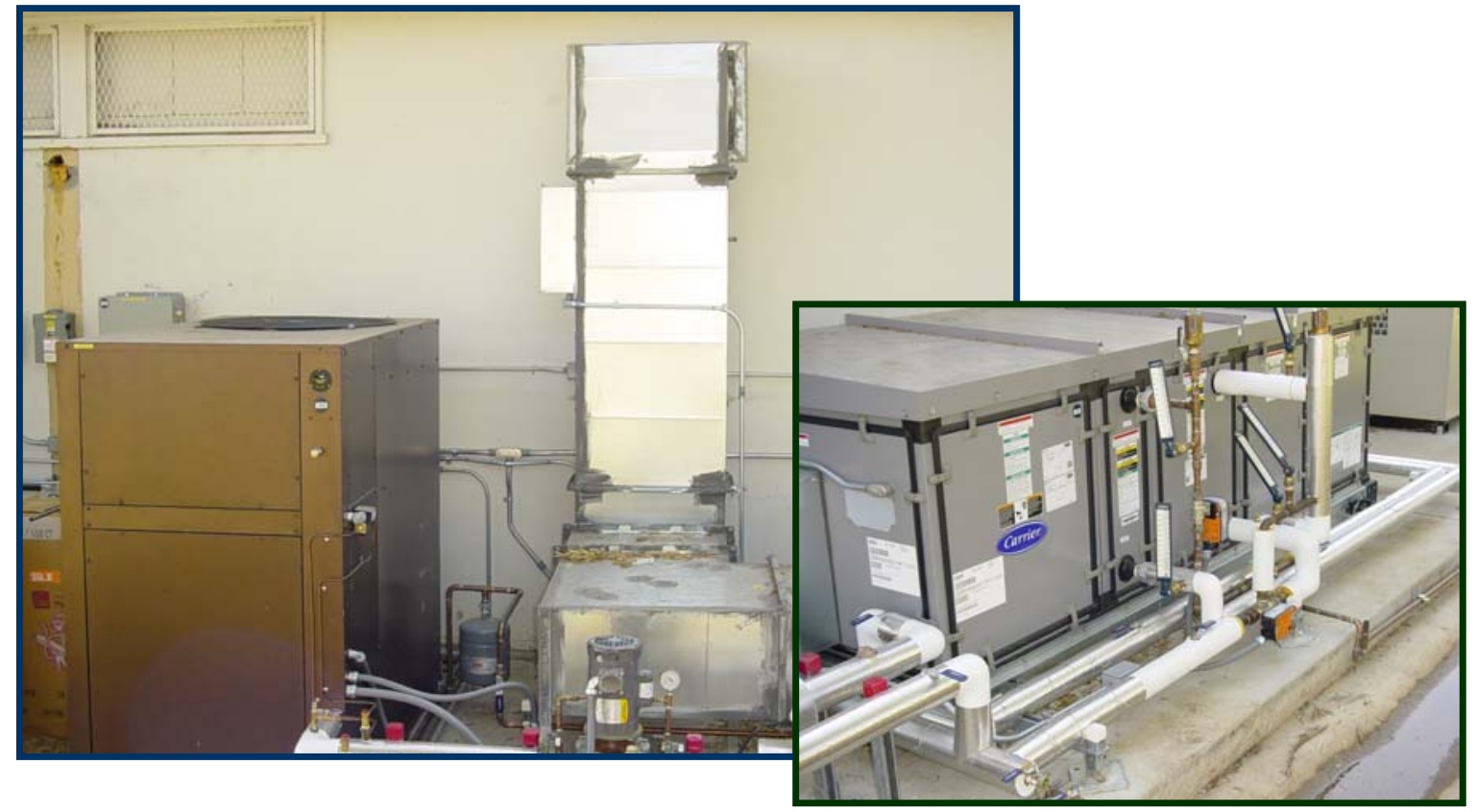

Figure 4. Installation just outside Building C539, NSWC Corona

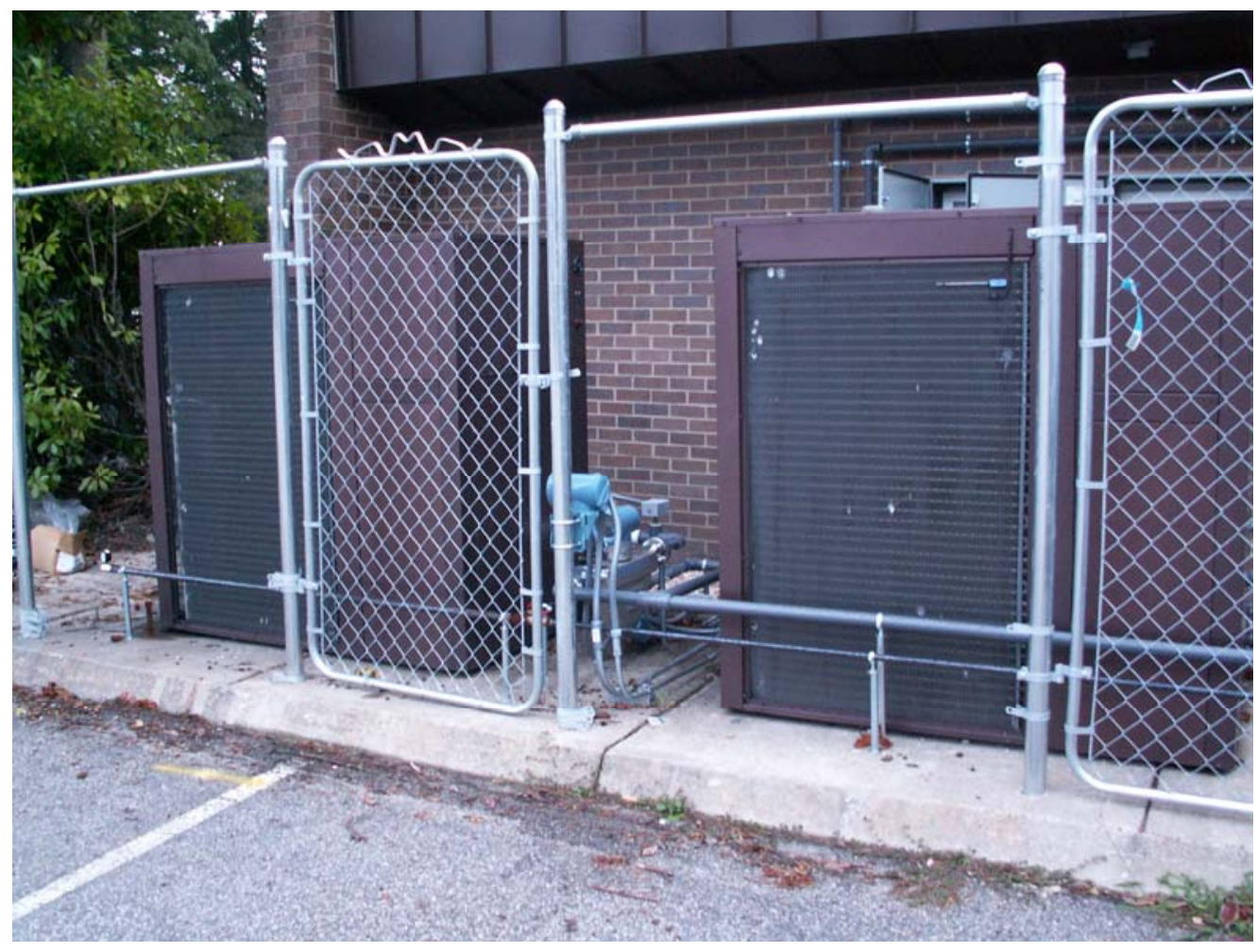

Figure 5. Installation just outside kitchen and laundry area of Building 3364, NAB Little Creek 


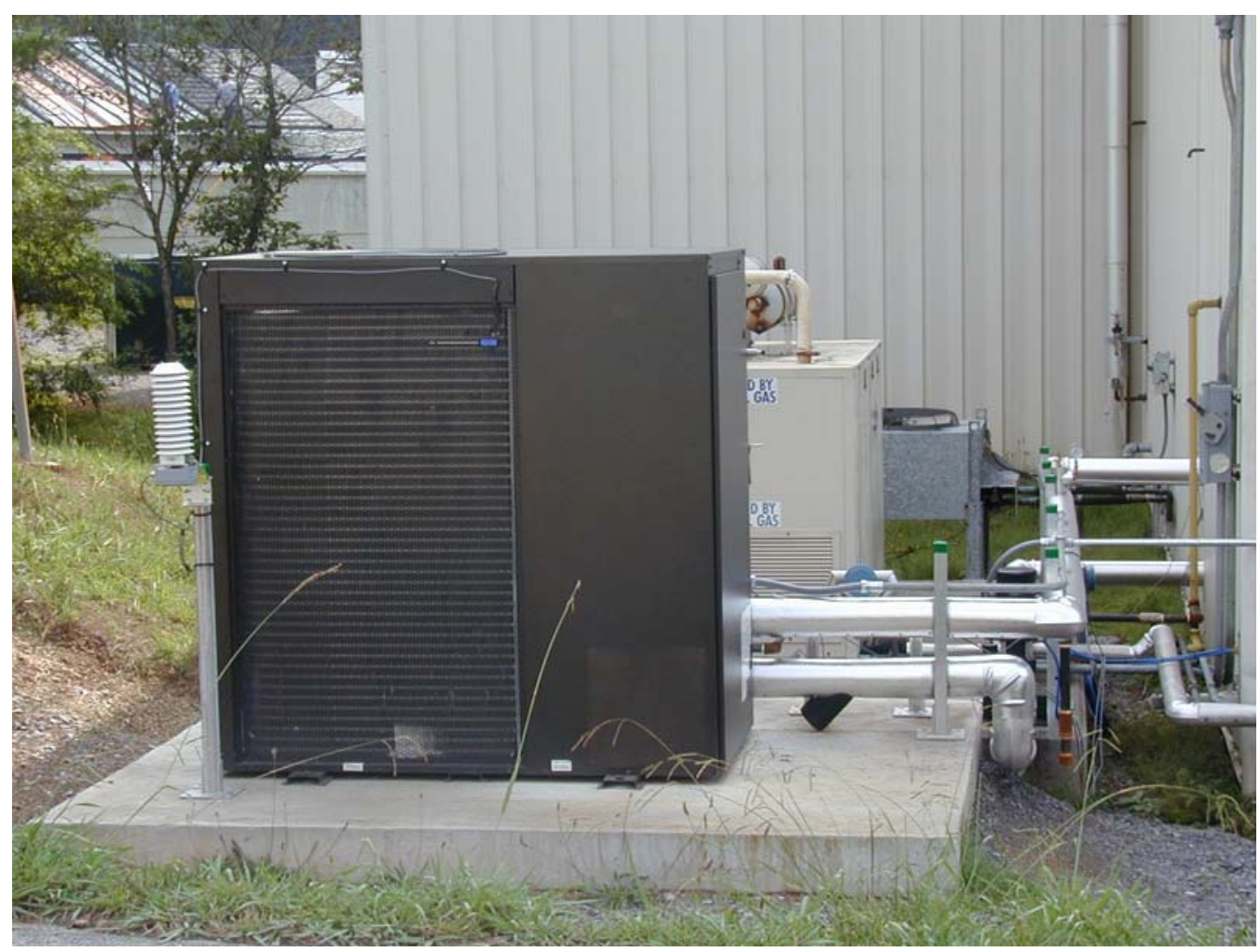

Figure 6. Installation outside Building 3144A, ORNL

\section{Control Strategies}

A detailed discussion of ORNL's development of the link controller theory for the gas-fired, 5ton, aqua-ammonia chillers is described in the Task 3 report. Because of the chiller's ability to reduce firing (and capacity) at an increased COP, a simple control that turns chillers on or off depending on the chilled water supply temperature is not optimal. For these chillers, it is advantageous to modulate each chiller in the link to a minimum firing rate before turning it off. By staging in this manner, dramatically higher operating COP with reduced parasitic (electric) power consumption will result. This also reduces the degradation in COP that results from transient cycling of individual chillers.

The development of the link controller theory began with the development of the control theory for each individual chiller with respect to load. An indicator of the load versus the capacity of the chiller is the chilled water supply temperature. Therefore, we developed a control theory for each individual chiller's operation as a function of the chilled water supply temperature. This basis in the single chiller's control provided a necessary segue to the rationale involved in controlling multiple chillers that collectively contribute their cooling capacity to a unified chilled water utility. The link controller uses this turndown logic, and also has the capability to interpret inputs from one or more conventional on-off thermostats in indoor zones. The notion embraced by this control theory is that the methods utilized in the logic of a single chiller controller to this end include a subset of the methods used by a link controller when in command of multiple chiller units. 
The link control hardware largely emulates the existing chiller controllers in terms of motor control methods and thermostat inputs. The hardware is entirely solid-state. Electrical isolation is provided as necessary to conform to safety and performance standards, as well as to maintain longevity of controller components. The logic is embodied in a microchip technology microcontroller device, and fast, efficient CMOS technology is prevalent for data transfer with low power consumption. A potentially comprehensive operator interface has been developed for the system to maximize maintainability and user-friendliness for field technicians.

The details of the basis and mathematics for effective zone control as well as multiple chiller control are described in the Task 3 report. This control strategy includes flexibility options for indoor air handler equipment including variable- and fixed-speed circulating fans. For maximized efficiency and effective humidity control, new construction should exploit the use of variable-speed technology. Several manufacturers produce fan motors that have electronically commutated motor technology. The efficiency of these motors increases dramatically with decreased speed, unlike permanent split capacitor motors when subject to phase modulation speed control. This controller hardware provides sets of both types of output and is capable of serving a reasonable number of zones containing either or both types of fan motors.

The chiller link controller will be evaluated in the field at Little Creek, which will use automated logic control and Web control for remote monitoring.

\section{Technology Performance}

\subsection{Data Collection}

The requirements/specifications for the5-ton absorption chiller are as follows:

\section{Electrical ratings}

Rated voltage (60 Hz single phase)

Minimum circuit amps

Maximum over current protection

Condenser fan (full load/locked rotor amps)

Total electrical consumption at rating conditions

\section{Performance/Ratings}

Cooling capacity (at $95^{\circ} \mathrm{F}$ outdoor rating condition)

Gas heat input (nominal at rating condition)

Chilled water flow rate (nominal)

Chilled water entering temperature

Chilled water leaving temperature

Maximum/minimum gas supply pressure

Maximum chilled water inlet pressure

Refrigerant
$208 \mathrm{~V}$

$10.0 \mathrm{~A}$

$20.0 \mathrm{~A}$

$5.1 / 11.0 \mathrm{~A}$

$1.2 \mathrm{~kW}$

5-ton $(60,000 \mathrm{Btu} / \mathrm{h})$
$85,700 \mathrm{Btu} / \mathrm{h}$
$12 \mathrm{gpm}$
$55^{\circ} \mathrm{F}$
$45^{\circ} \mathrm{F}$
$14.0 / 5.0$ in. water column
$50 \mathrm{psig}$
R717 (ammonia)

5-ton $(60,000 \mathrm{Btu} / \mathrm{h})$

$\mathrm{Btu} /$

$45^{\circ} \mathrm{F}$

50 psig

R717 (ammonia)

Major instrumentation for these field tests for data retrieval, storage and analysis includes but is not limited to the following components:

Temperatures

Chilled water supply

Chilled water return 
Outdoor ambient temperature

Indoor space temperature

Humidity

Outdoor humidity sensor (relative humidity)

Indoor space humidity sensor (relative humidity)

Flow rates

Natural gas flow (mass flow meters) with $<0.2$ psi pressure drop at the gas flow of the absorption unit at rating condition

Water flow (mass flow meters)

Power consumption

Power consumption (Watt-transducers, W)

Sensors used for these measurements and associated accuracies are shown in Table 1. The required accuracy of the test instrumentation is in accordance with American Society of Heating, Refrigerating and Air-conditioning Engineers (ASHRAE) and/or ASME documents. The data acquisition system calculated and displayed important parameters such as the temperature, humidity, flow rate, gas input, cooling capacity, electrical power use, and gas COP.

\subsection{Laboratory Performance}

An Ambian chiller (beta unit \#3) was received, installed, and instrumented in the ORNL Environmental Chambers with the help of the manufacturer (June 2004). The air-cooled absorption unit was installed in the larger room (outdoor chamber) with the air-handler unit (AHU) in the smaller room (indoor chamber). A chilled water loop connected the AHU to the absorption unit (Figure 7). The absorption unit was operated in a controlled laboratory environment over a wide range of ambient conditions including the operating conditions for standard rating and performance tests (ARI Standard 210/240-94, March 26, 1998) (see Table 2). Results are average values of 1-hour performance data at 1-minute intervals once steady-state condition was achieved. Daily values of the heating content of the natural gas from the local gas company were used to calculate the gas input to the unit.

Figures 8 and 9 show the capacity and COP of this Ambian unit (beta unit \#3) at various ambient conditions along with comparable data from beta unit \#13 tested previously under the DOE program. Performance data show the close agreement between these two pre-commercial Ambian units. The capacity of these units was found to be approximately 56,500 Btu/h with a $\mathrm{COP}$ of 0.66 at the standard rating of $95^{\circ} \mathrm{F}$ outdoor condition, which is within the accuracy range of the instrumentation at the desired performance levels for both capacity and COP. In addition, this unit was operated at " $C$ " cooling condition (steady state, dry coil) as outlined in Table 2. At this condition, the unit was using its modulating burner capability to optimize its performance by maintaining the chilled water temperature at around $45^{\circ} \mathrm{F}$. The COP and capacity were found to be 0.72 and $48,000 \mathrm{Btu} / \mathrm{h}$ respectively. When the unit was forced to operate at a low firing rate (jumper on the control box), then the unit operated with a COP of 0.84 and capacity of 42,000 $\mathrm{Btu} / \mathrm{h}$. Figure 10 shows the emissions from the pre-commercial unit (beta \#3). The CO concentration was found to be 8 ppmv and the $\mathrm{NO}_{\mathrm{x}}$ concentration less than $13 \mathrm{ppmv}$. 
Table 1. Major test instrumentation and measurement accuracies

\begin{tabular}{|c|c|c|c|}
\hline Measurement & Sensor & Range & Accuracy \\
\hline Temperature & Immersion thermistors & -67 to $302^{\circ} \mathrm{F}$ & $\begin{array}{c} \pm 0.4^{\circ} \mathrm{F} \\
\left(32 \text { to } 158^{\circ} \mathrm{F}\right)\end{array}$ \\
\hline Coolant flow & $\begin{array}{l}\text { Coriolis mass flow } \\
\text { sensor }\end{array}$ & 0 to $14,000 \mathrm{lb} / \mathrm{h}$ & $\pm 0.1 \%$ \\
\hline Natural gas flow & $\begin{array}{l}\text { Coriolis mass flow } \\
\text { sensor }\end{array}$ & 0 to $5 \mathrm{lb} / \mathrm{h}$ & $\pm 0.1 \%$ \\
\hline $\begin{array}{l}\text { Outdoor } \\
\text { temperature/humidity (with } \\
\text { radiation shield) }\end{array}$ & & & \\
\hline Dry-bulb temperature & $\begin{array}{l}\text { Resistance temperature } \\
\text { detectors (RTD) PT100 }\end{array}$ & -40 to $140^{\circ} \mathrm{F}$ & $\pm 0.4^{\circ} \mathrm{F}$ \\
\hline Relative humidity & $\begin{array}{l}\text { Capacitive thin-film } \\
\text { humidity sensor }\end{array}$ & $\begin{array}{c}0 \text { to } 90 \% \\
90 \text { to } 100 \%\end{array}$ & $\begin{array}{l} \pm 1.0 \% \\
\pm 1.7 \% \\
\end{array}$ \\
\hline $\begin{array}{l}\text { Indoor } \\
\text { temperature/humidity }\end{array}$ & & & \\
\hline Dry-bulb temperature & $\begin{array}{l}\text { Resistance temperature } \\
\text { detectors (RTD) PT100 }\end{array}$ & -40 to $140^{\circ} \mathrm{F}$ & $\pm 0.4^{\circ} \mathrm{F}$ \\
\hline Relative humidity & $\begin{array}{l}\text { Capacitive thin-film } \\
\text { humidity sensor }\end{array}$ & $\begin{array}{c}0 \text { to } 90 \% \\
90 \text { to } 100 \%\end{array}$ & $\begin{array}{l} \pm 1.0 \% \\
\pm 1.7 \%\end{array}$ \\
\hline Electric power & Watt transducer & 0 to $2 \mathrm{~kW}$ & $\pm 0.5 \%$ \\
\hline
\end{tabular}

Table 2. Operating Conditions Used for Evaluation of Advanced Ammonia/Water Chillers Test Conditions

tandard rating conditions

"A" Cooling steady state ${ }^{a}$

"B" Cooling steady state ${ }^{a}$

"C" Cooling steady state

Dry coil ${ }^{a}$

High ambient temperature 1

High ambient temperature 2

High ambient temperature 3

\begin{tabular}{|c|c|}
\hline \multicolumn{2}{|c|}{$\begin{array}{l}\text { INDOOR UN } \\
\text { Air Enterin }\end{array}$} \\
\hline $\begin{array}{c}\text { Dry } \\
\text { Bulb } \\
\left({ }^{\circ} \mathrm{F}\right) \\
80.0\end{array}$ & $\begin{array}{c}\text { Dew } \\
\text { Point } \\
\left({ }^{\circ} \mathrm{F}\right) \\
60.2\end{array}$ \\
\hline 80.0 & 60.2 \\
\hline 80.0 & 36.8 \\
\hline 80.0 & 60.2 \\
\hline 80.0 & 60.2 \\
\hline 80.0 & 60.2 \\
\hline
\end{tabular}

OUTDOOR UNIT

OUTDOOR UNI

Wet

Bulb

( $\left.{ }^{\circ} \mathrm{F}\right)$

67.0

67.0

$57.0^{c}$

67.0

67.0

67.0

Dry

Dew

Bulb Point Bulb

( $\left.{ }^{\circ} \mathrm{F}\right)$

( $\left.{ }^{\circ} \mathrm{F}\right)$

( $\left.{ }^{\circ} \mathrm{F}\right)$

95.0

66.5

$75.0^{b}$

${ }^{a}$ Operating Conditions for Standard Rating and Performance Tests (ARI Standard 210/240-94, March 26, 1998).

${ }^{b}$ Wet bulb temperature condition is not required

${ }^{c}$ Wet bulb sufficiently low that no condensate forms on evaporator. 


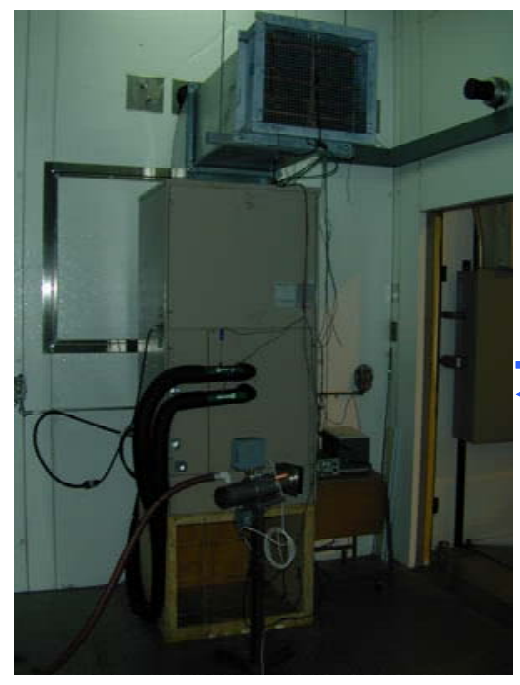

Air-Handler Unit (AHU) In Indoor Chamber

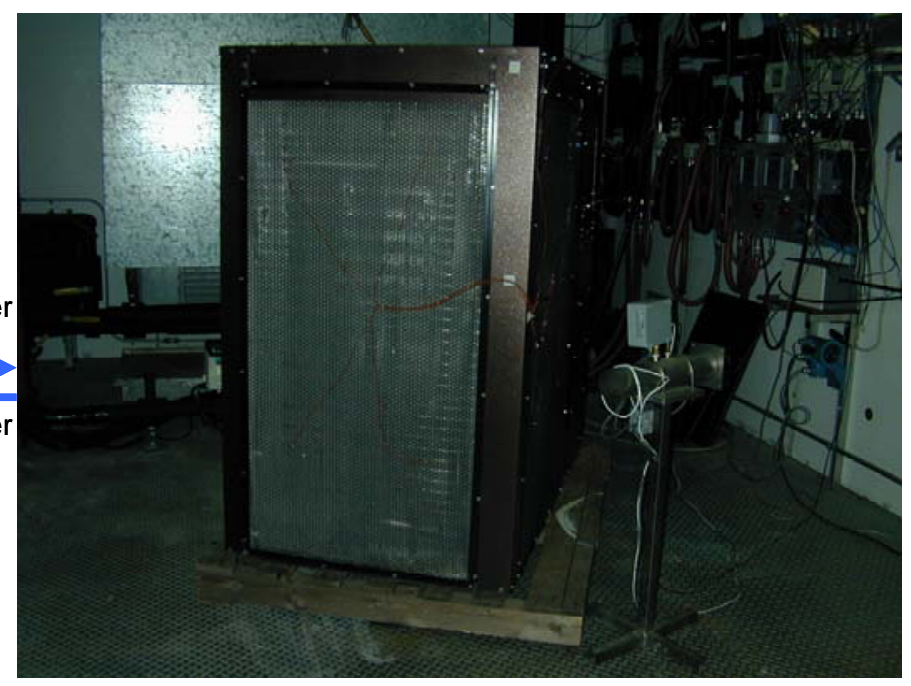

5-Ton Pre-Commercial Chiller In Outdoor Chamber

Figure 7. Set-up used for performance evaluation.

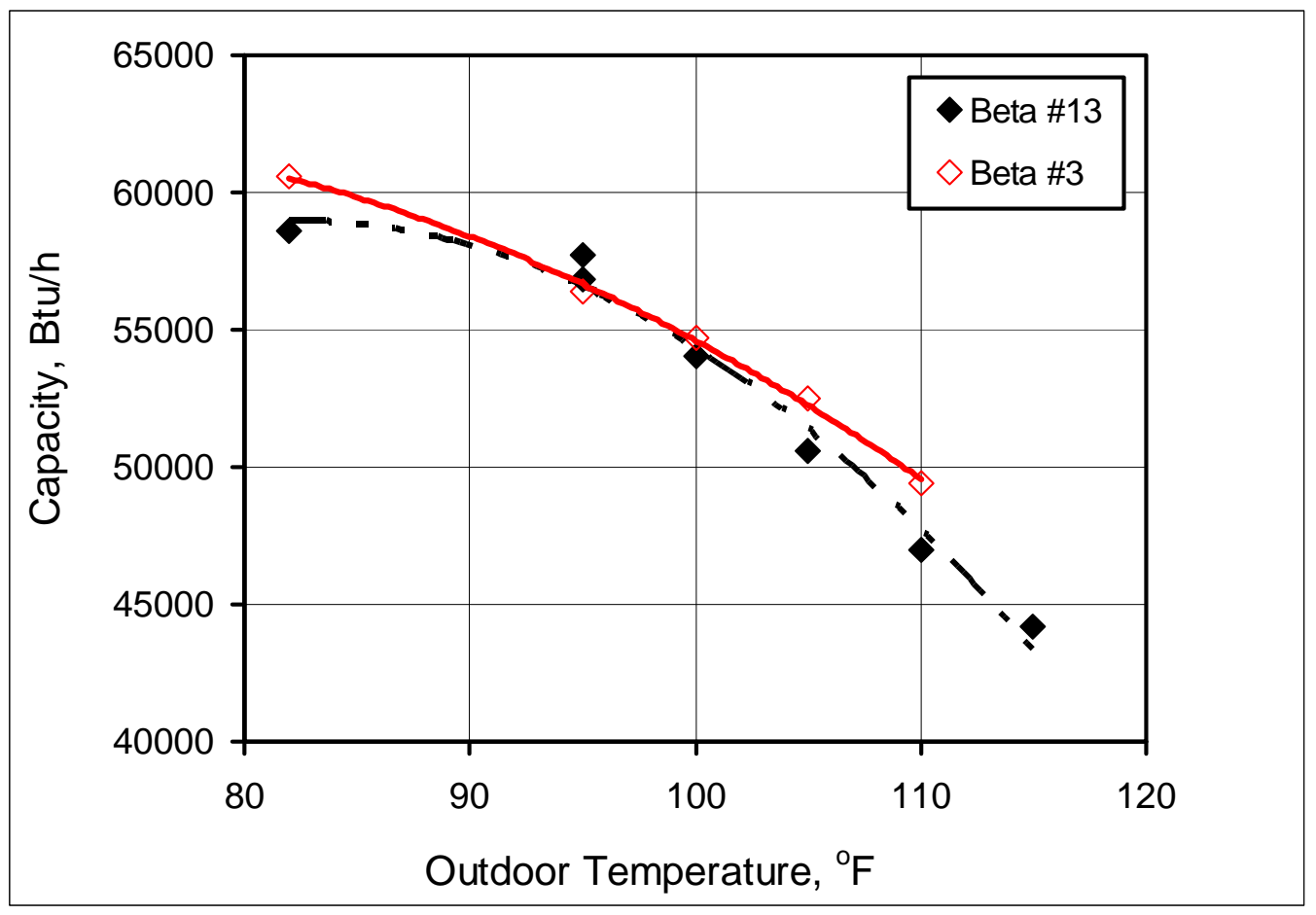

Figure 8. Capacity of pre-commercial units (beta units). 


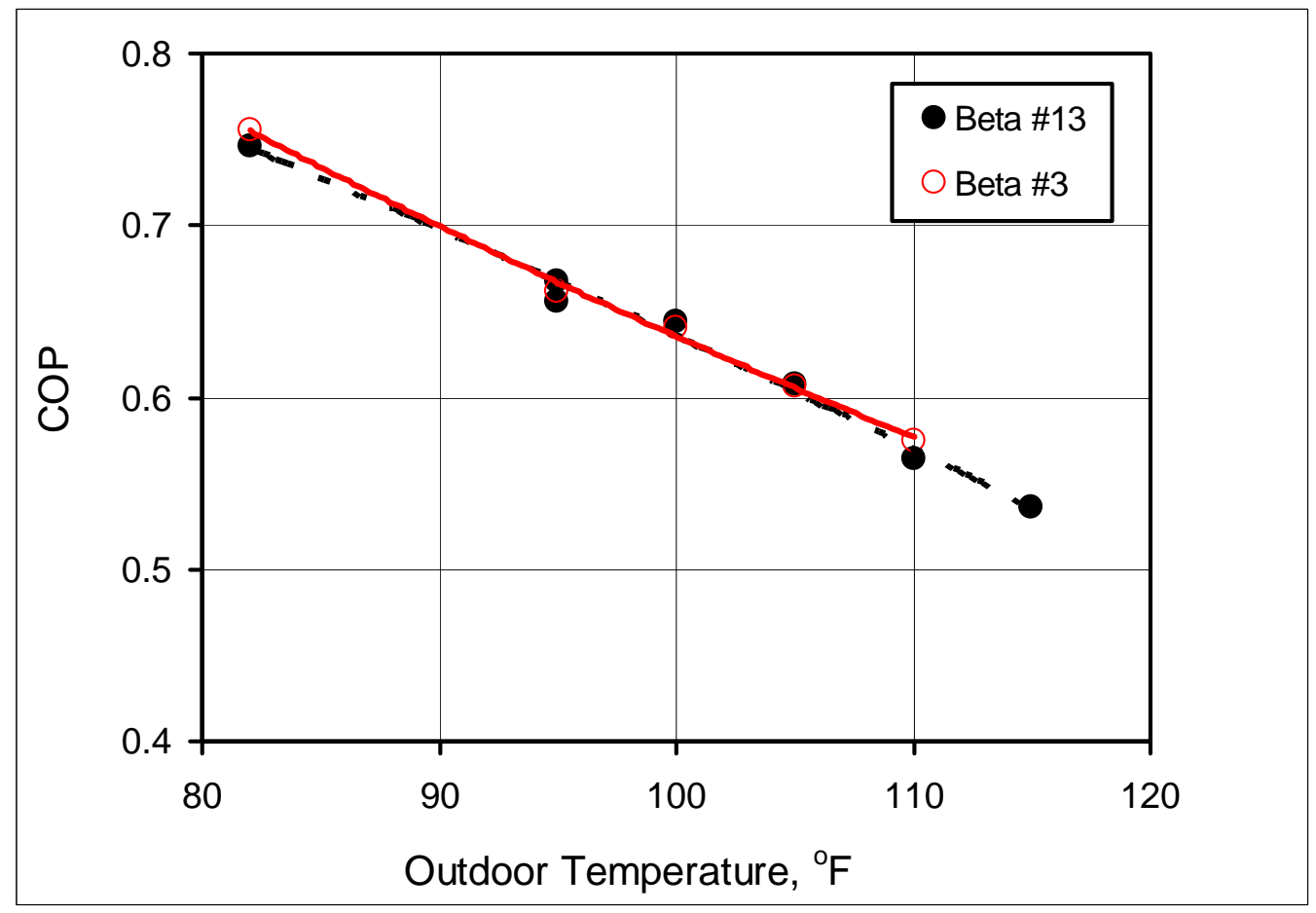

Figure 9. Coefficient of performance (COP) of pre-commercial units (beta units).

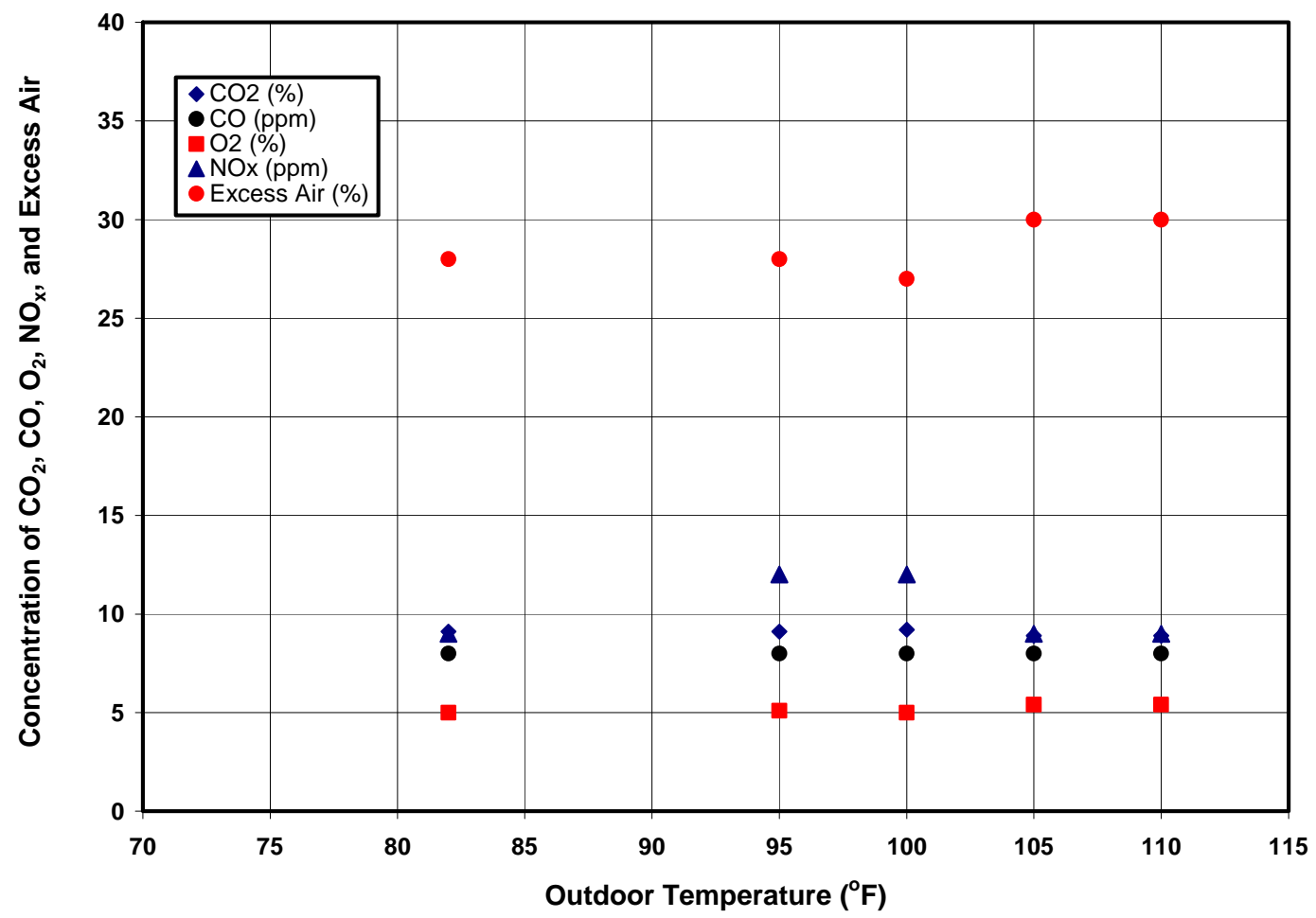

Figure 10. Flue gas composition of pre-commercial unit (beta \#3). 
Overall, Ambian chillers operated well over a wide range of ambient conditions in the controlled laboratory environment with minimal degradation as a result of the use of several control strategies, such as a variable-speed condenser fan, a modulating burner, and active refrigerant flow control (a thermostatic expansion valve [TXV]). However, the durability and availability of these Ambian pre-commercial units in the field are still unknown, so all three field tests had a redundant system as a back-up.

\subsection{Field Experience, NSWC Corona}

A 5-ton, aqua-ammonia, absorption chiller was shipped to NSWC Corona in December 2004 after extensive pre-testing at Rocky Research. When installed in April 2005, the chiller had 694.6 burner operating hours. The chiller ran for 3342.3 burner operating hours at the host site for two cooling seasons (summer of 2005 and 2006) before its removal in March 2007.

\section{Performance Test Results}

After initial commissioning and troubleshooting, the operation of the unit started in June 2005. Field test data were being collected at 1-minute intervals using a Campbell Scientific data logger with a modem. The field data were then converted to hourly data for bin analysis. The heating content of the natural gas (higher heating value or HHV) was assumed to be constant at 1020 $\mathrm{Btu} / \mathrm{scfm}$.

Figures 11-18 show examples of the performance of the chiller. The large COPs shown are the result of residual cooling even after the gas burner has been cycled off. Table 3 shows a bin analysis of the performance data at NSWC Corona. The electrical power use of the unit was found to be $0.6 \mathrm{~kW}$ or less. The COP was found to be greater than 0.63 with a cooling capacity of 38,622 Btu/h (3.2 RT) or higher. Unfortunately, the expected load in the building did not continue, which made the 5-ton unit too large for the space to be cooled. This change resulted in poor thermostat control and low chilled water temperatures that cycled the chiller off on lowtemperature cutout at times. These issues resulted in cycling losses and lower than expected performance.

$\begin{array}{cccc}\begin{array}{c}\text { Bin data } \\ \text { ( }{ }^{\circ} \text { F) }\end{array} & \begin{array}{c}\text { Table 3. Performance data at NSWC Corona } \\ \text { Gas }\end{array} & \begin{array}{c}\text { Cooling capacity } \\ \text { (Btu/h) }\end{array} & \begin{array}{c}\text { Power used } \\ \text { (kW) }\end{array} \\ 65-69 & 0.673 & 38,622 & 0.34 \\ 70-74 & 0.703 & 40,976 & 0.38 \\ 75-79 & 0.631 & 37,996 & 0.41 \\ 80-84 & 0.657 & 39,156 & 0.47 \\ 85-89 & 0.686 & 43,594 & 0.58 \\ 90-94 & 0.733 & 41,496 & 0.59\end{array}$




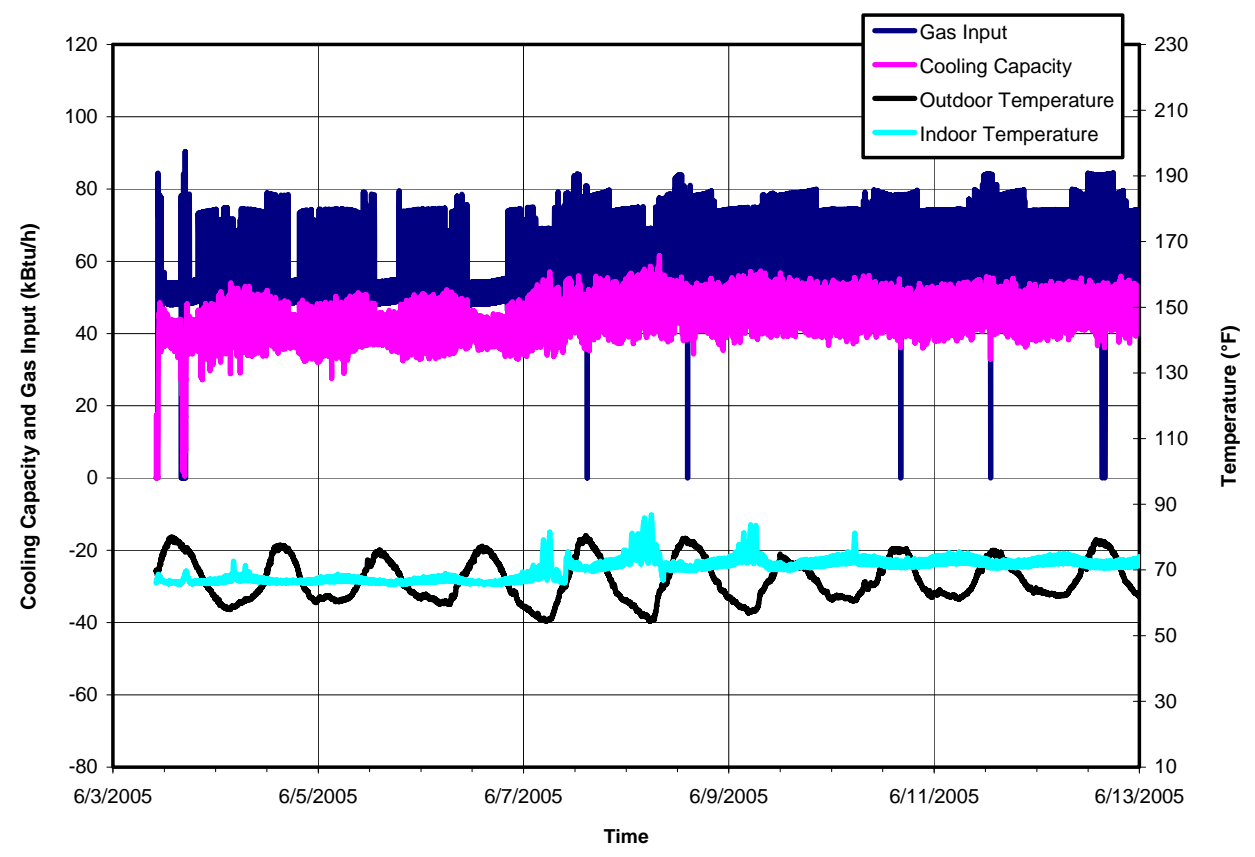

Figure 11. Cooling capacity of the aqua-ammonia chiller at NSWC Corona, June 3 to 13, 2005.

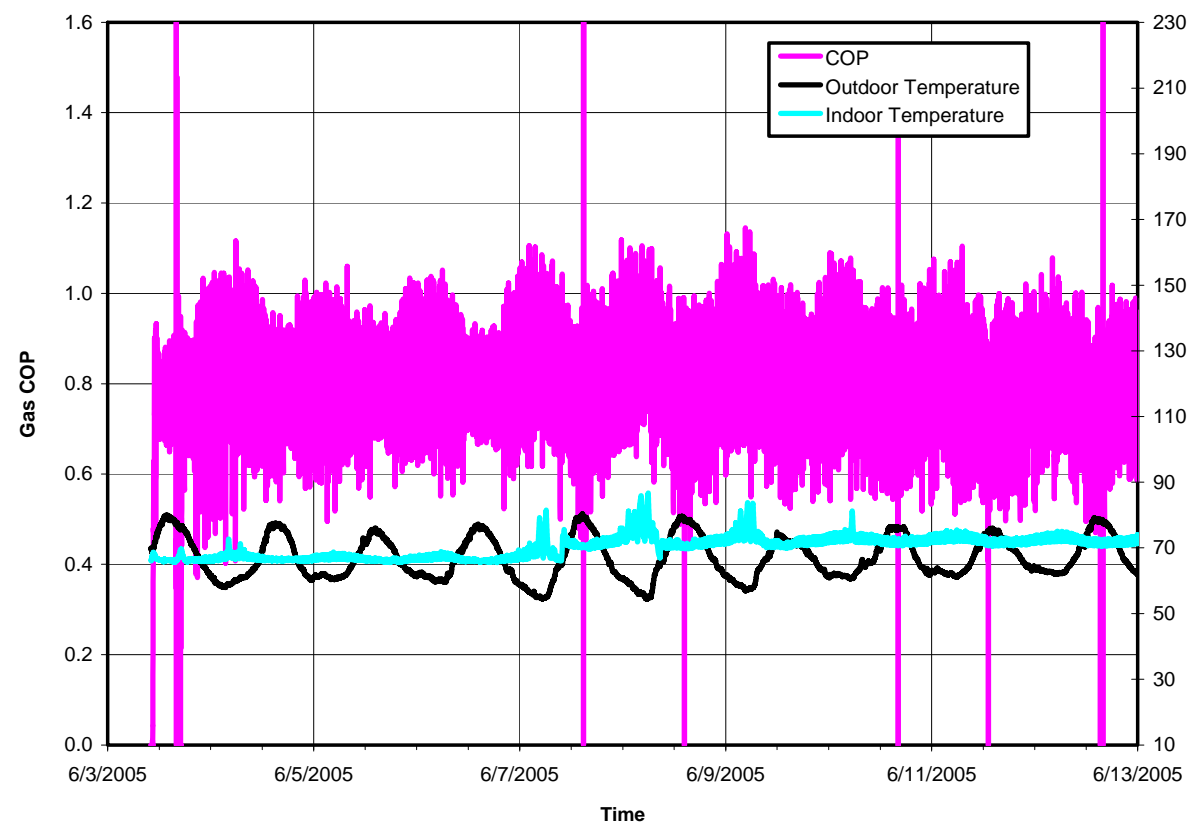

Figure 12. Cooling gas COP of the aqua-ammonia chiller at NSWC Corona, June 3 to 13, 2005. 


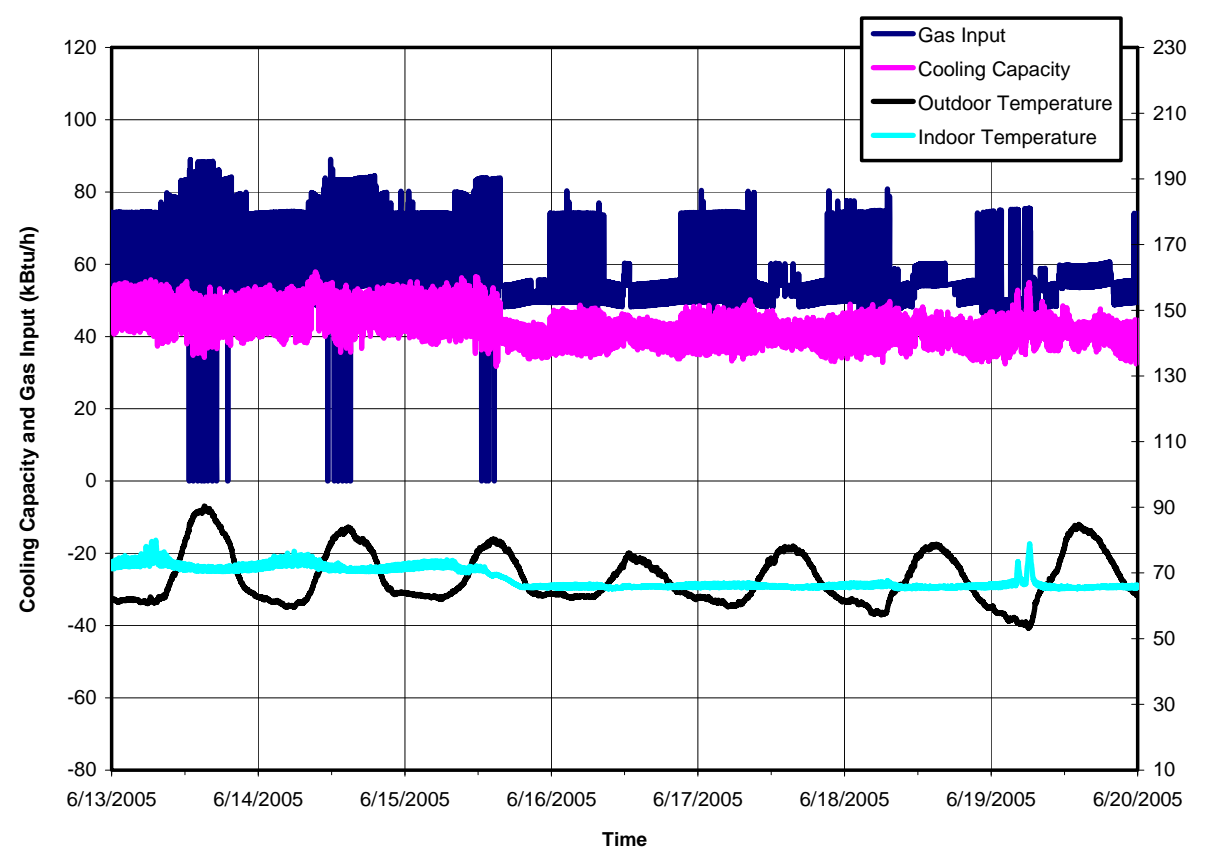

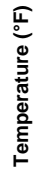

Figure 13. Cooling capacity of the aqua-ammonia chiller at NSWC Corona, June 13 to 20, 2005.

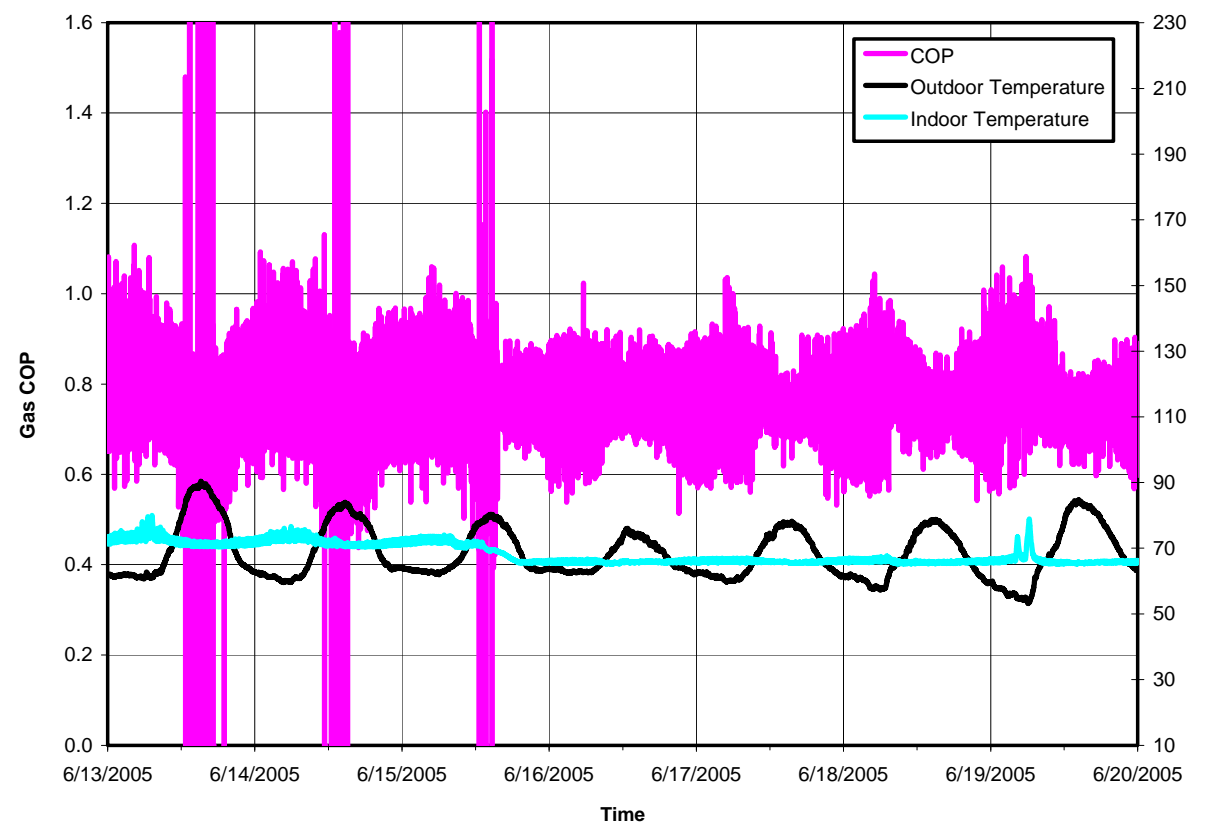

Figure 14. Cooling gas COP of the aqua-ammonia chiller at NSWC Corona, June 13 to 20, 2005. 


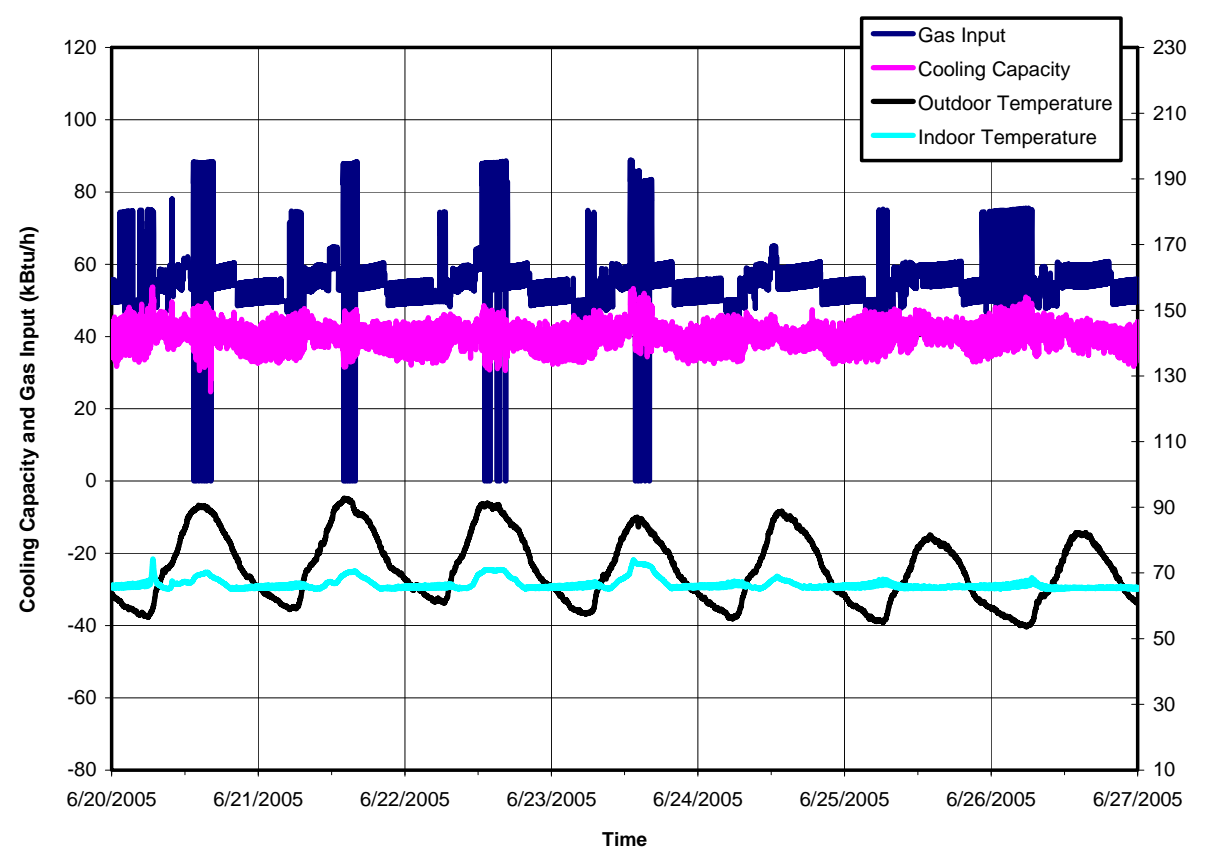

Figure 15. Cooling capacity of the aqua-ammonia chiller at NSWC Corona, June 20 to 27, 2005.

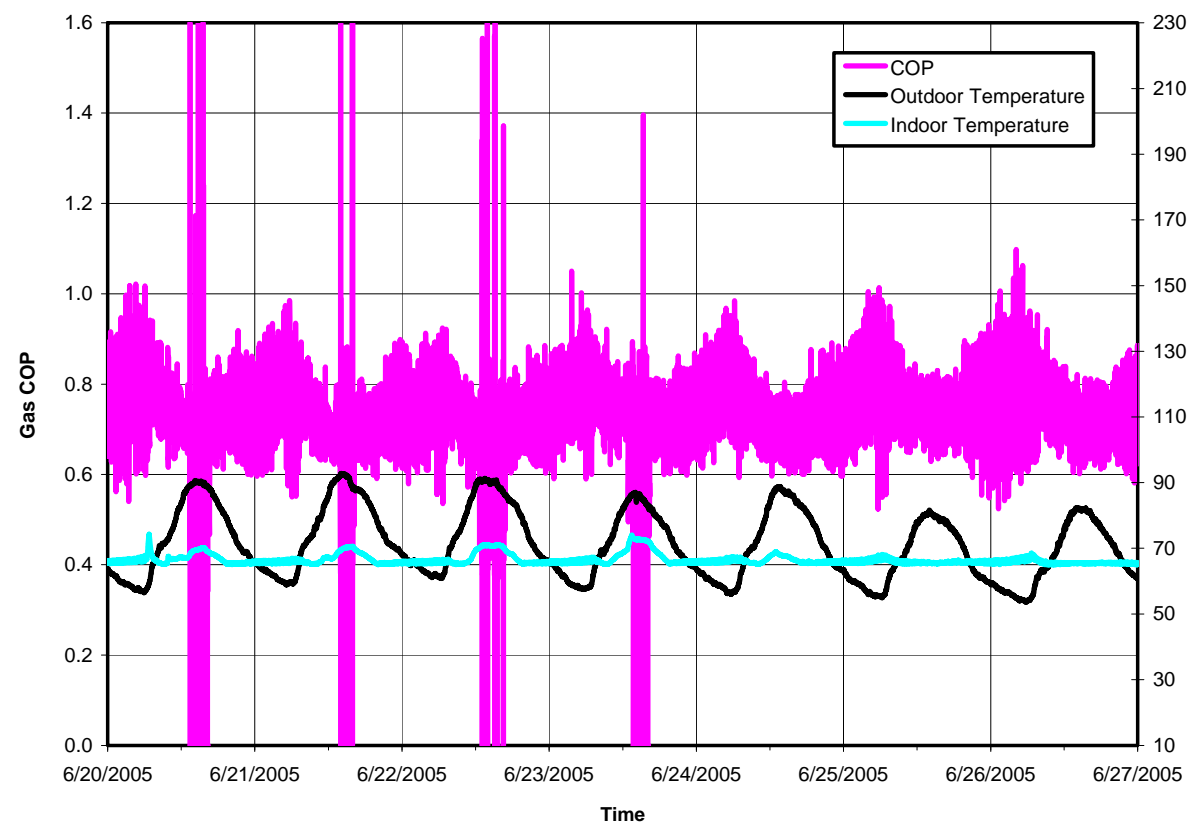

Figure 16. Cooling gas COP of the aqua-ammonia chiller at NSWC Corona, June 20 to 27, 2005. 


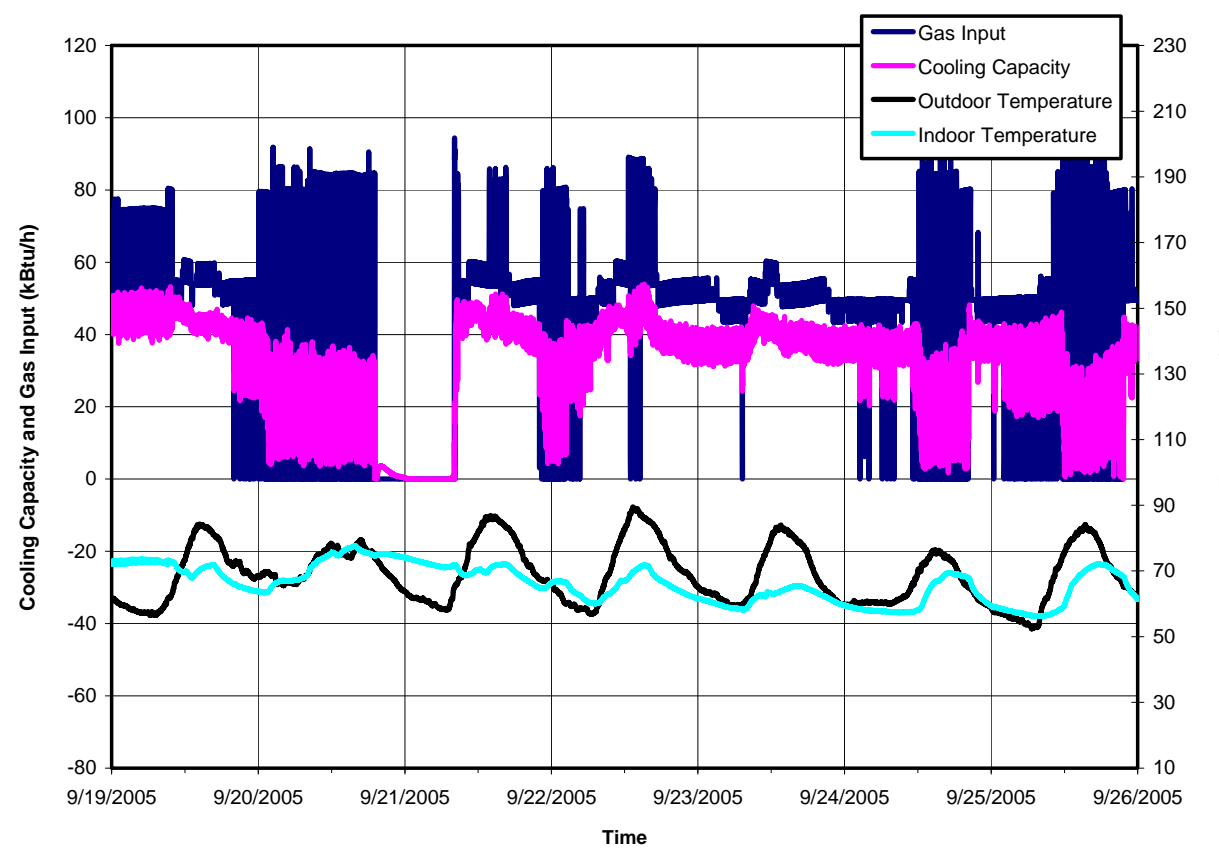

Figure 17. Cooling capacity of the aqua-ammonia chiller at NSWC Corona, September 19 to 26, 2005.

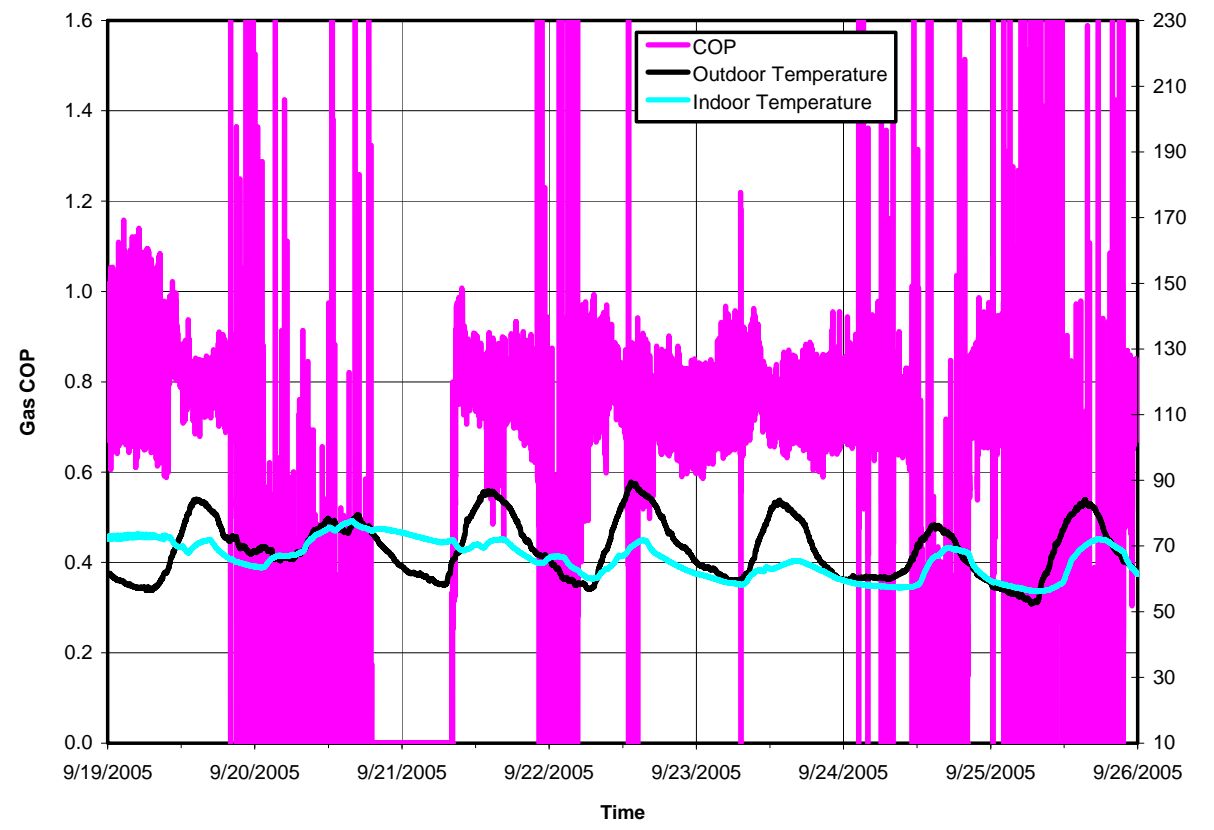

Figure 18. Cooling gas COP of the aqua-ammonia chiller at NSWC Corona, September 19 to 26, 2005. 
The unit operated well in the first cooling season but unfortunately did not have the same type of success in the second cooling season, even after multiple maintenance/service calls by Rocky Research personnel. To resolve the dependability/reliability issues, the absorption chiller was sent to Rocky Research for destructive evaluation. Some of the issues at the NSWC Corona installation were as follows:

1. The thermostat control at the host site did not function properly, and the zone valve associated with it did not provide the necessary flow rate to the chiller at all times. This resulted in some low chilled water temperatures that cycled the chiller off on lowtemperature cutout at times.

2. The solenoid valve seal was replaced with Teflon, which has less chance of deformation.

3. The active refrigerant flow control made noise at times. The source of this noise has been identified and mitigated on future units.

4. A solution pump check valve spring broke, and consequently the pump was replaced. Subsequently, it was determined that this spring is unnecessary, and the part has been eliminated in favor of gravity sealing.

5. No burner/combustion chamber problems were observed. An adjustment to the burner was made, however, to account for altitude differences between the test location and Rocky Research's facility.

6. The ambient air temperature sensor was shaded to eliminate the solar heating effect on temperature data. This will not be an issue in future units because the new control system does not require an ambient temperature sensor.

7. Before its removal from NSWC Corona, the unit was shutting down because of low liquid levels in the generator. This unit was sent back to Rocky Research for destructive examination, which showed a small leak at a compression fitting that resulted in ammonia loss and in low levels in the generator. The number of compression fittings and shut-off valves will be minimized in future units.

\subsection{Field Experience, ORNL}

The installation of the second field test unit was completed at ORNL in May 2006. The chiller ran for 2,310.3 burner operating hours for two cooling seasons (summer of 2006 and 2007) before its decommissioning on July 2007.

\section{Performance Test Results}

After initial commissioning and troubleshooting, the operation of the unit started in June 2006. The performance data collected at 1-minute intervals were available on a password-protected Web site for remote monitoring by our sponsor and Rocky Research. The field data were then converted to hourly data for bin analysis. Daily values of the heating content of the natural gas from the local gas company were used to calculate the gas input to the unit.

Figures 19-30 show examples of the performance of the chiller. Table 4 shows a bin analysis of the performance data at ORNL. The electrical power use of the unit was found to be $1.6 \mathrm{~kW}$ or less. It should be noted that this included the power used by the coolant pump and several instruments (estimated to be approximately $0.8 \mathrm{~kW}$ ), which would make the power used by the chiller comparable to the results obtained at the NSWC Corona site. The unit operated well with a good load on the building with COPs of as high as 0.74 and capacity of as high as 55,040 Btu/h (4.6 RT). 


\begin{tabular}{|c|c|c|c|}
\hline \multirow[b]{2}{*}{ Bin Data } & \multicolumn{3}{|c|}{ 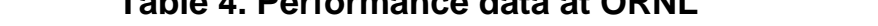 } \\
\hline & COP & Cooling (Btu/h) & Power (kW) \\
\hline $65-69$ & 0.746 & 50,300 & 1.00 \\
\hline $70-74$ & 0.737 & 52,882 & 1.04 \\
\hline $75-79$ & 0.739 & 55,040 & 1.18 \\
\hline $80-84$ & 0.704 & 54,041 & 1.35 \\
\hline $90-94$ & 0.664 & 52,544 & 1.48 \\
\hline 95-99 & 0.632 & 50,656 & 1.58 \\
\hline
\end{tabular}

The unit operated well during the first couple of months of operation, but later several issues started to appear: the active refrigerant flow control (TXV) made noise at times, the ambient air temperature sensor had to be shaded to eliminate the solar heating effect on temperature data, and several leaks developed from valves/compression fittings. The leaks resulted in low liquid levels in the generator, causing unexpected shutdowns. In the second cooling season, these issues were resolved by Rocky Research personnel. The TXV design was improved by increasing the orifice size to eliminate the noise. Minor adjustments to system charge inventories were also conducted to optimize system response to loading and ambient conditions. After these modifications, the unit operated well for a couple of months before another leak appeared. The fire tube of this unit seems to have developed a leak to the exhaust line for the flue gas. This unit will be sent to Rocky Research to confirm this finding.

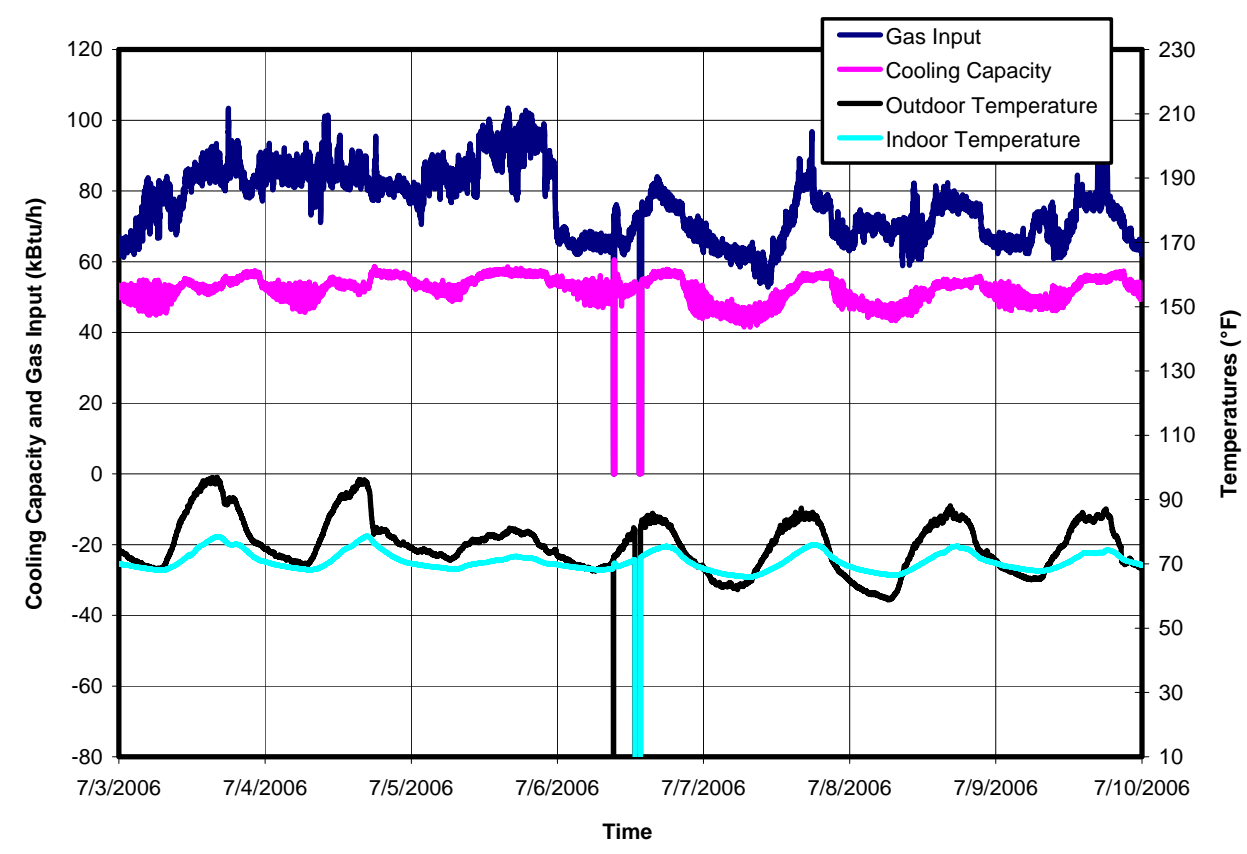

Figure 19. Cooling capacity of the aqua-ammonia chiller at ORNL, July 3 to $10,2006$. 


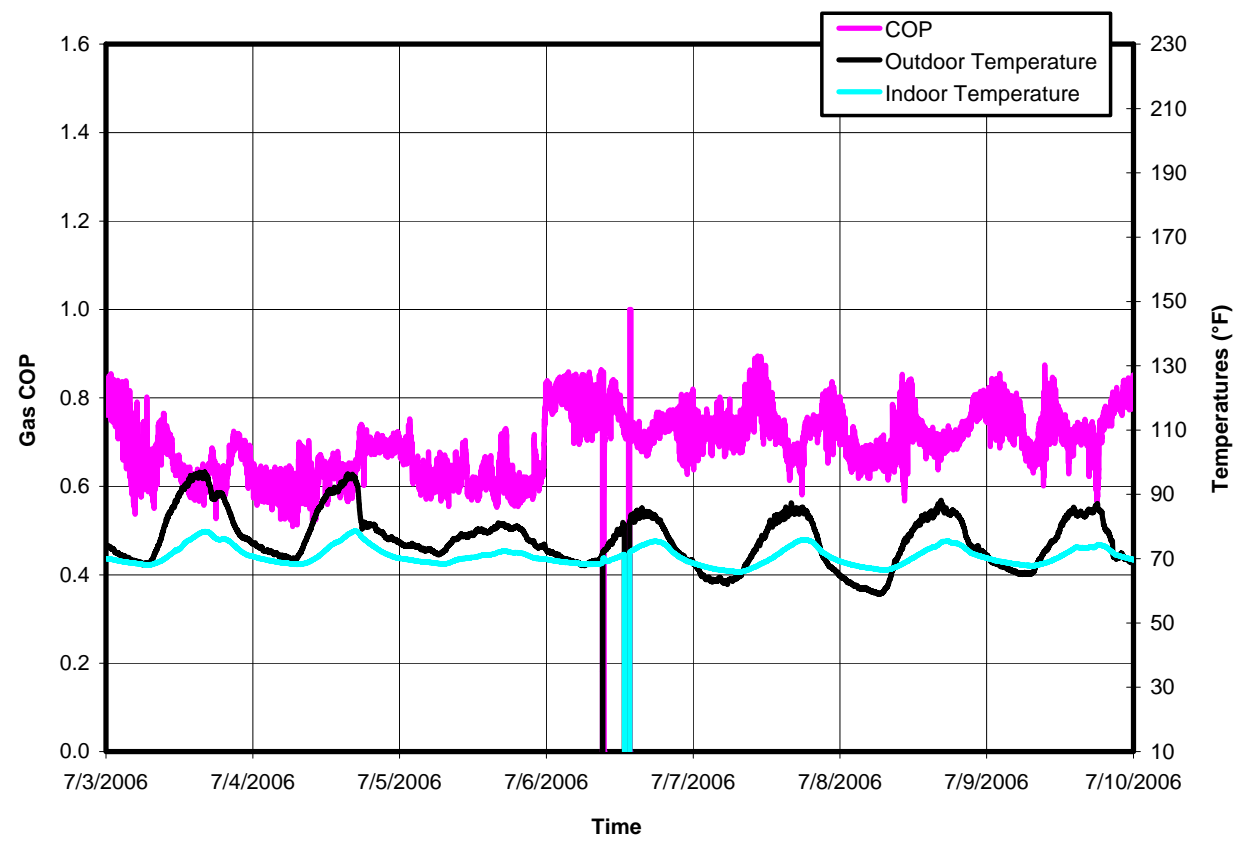

Figure 20. Gas COP of the aqua-ammonia chiller at ORNL, July 3 to 10, 2006.

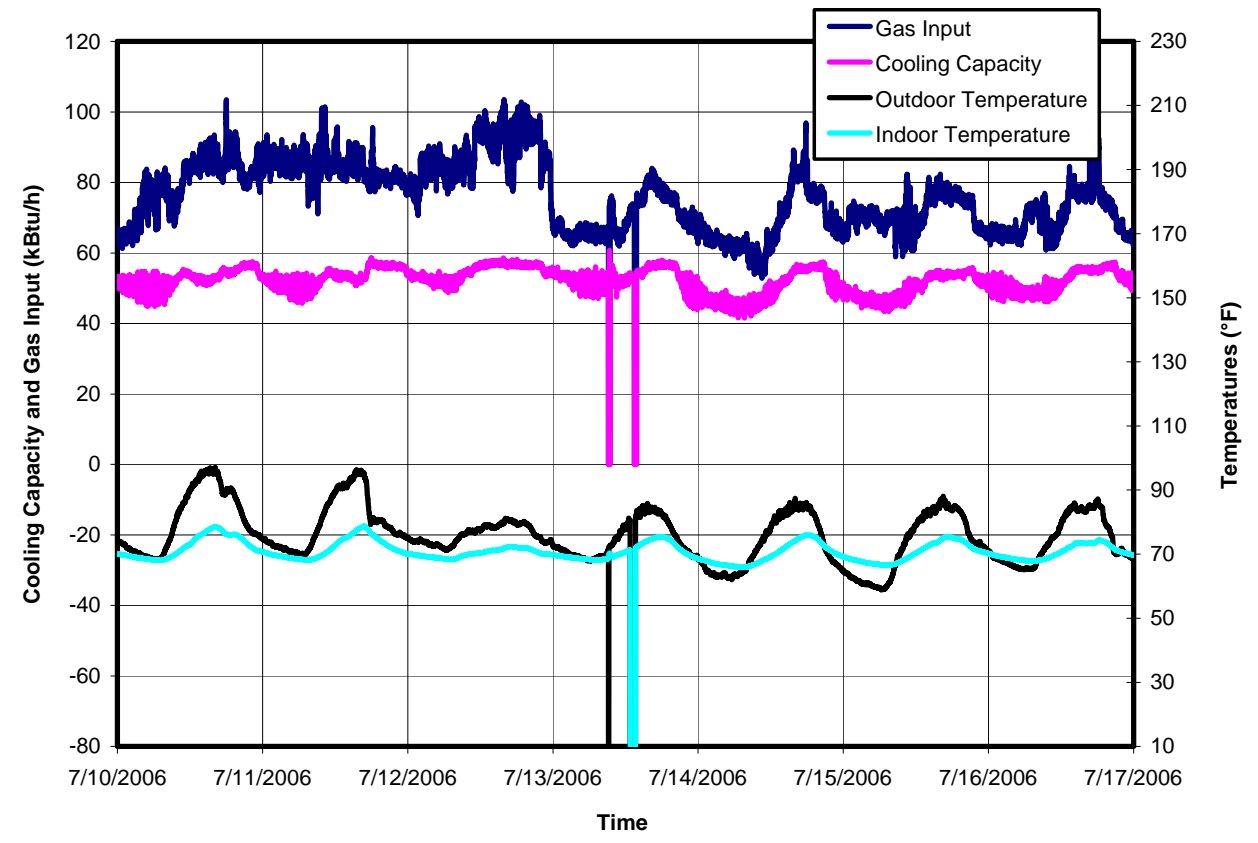

Figure 21. Cooling capacity of the aqua-ammonia chiller at ORNL, July 10 to $17,2006$. 


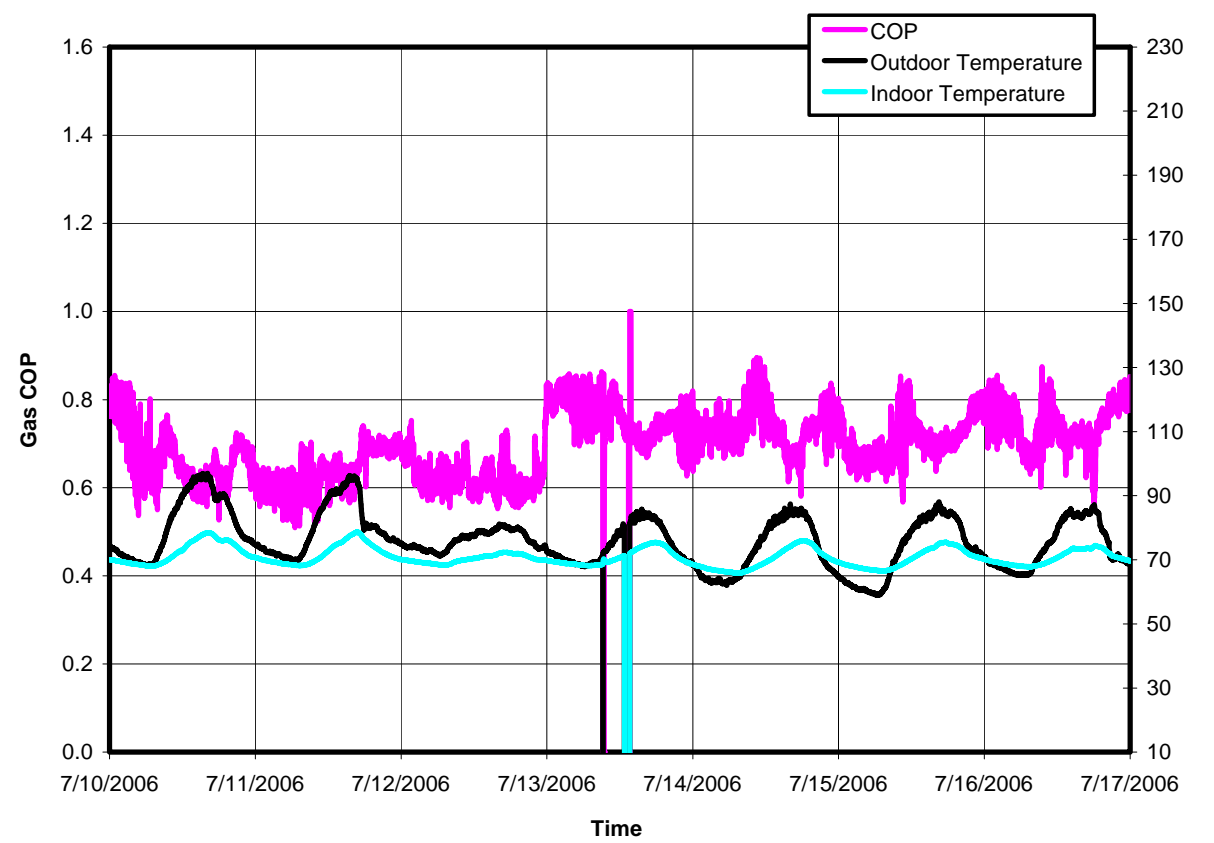

Figure 22. Gas COP of the aqua-ammonia chiller at ORNL, July 10 to $17,2006$.

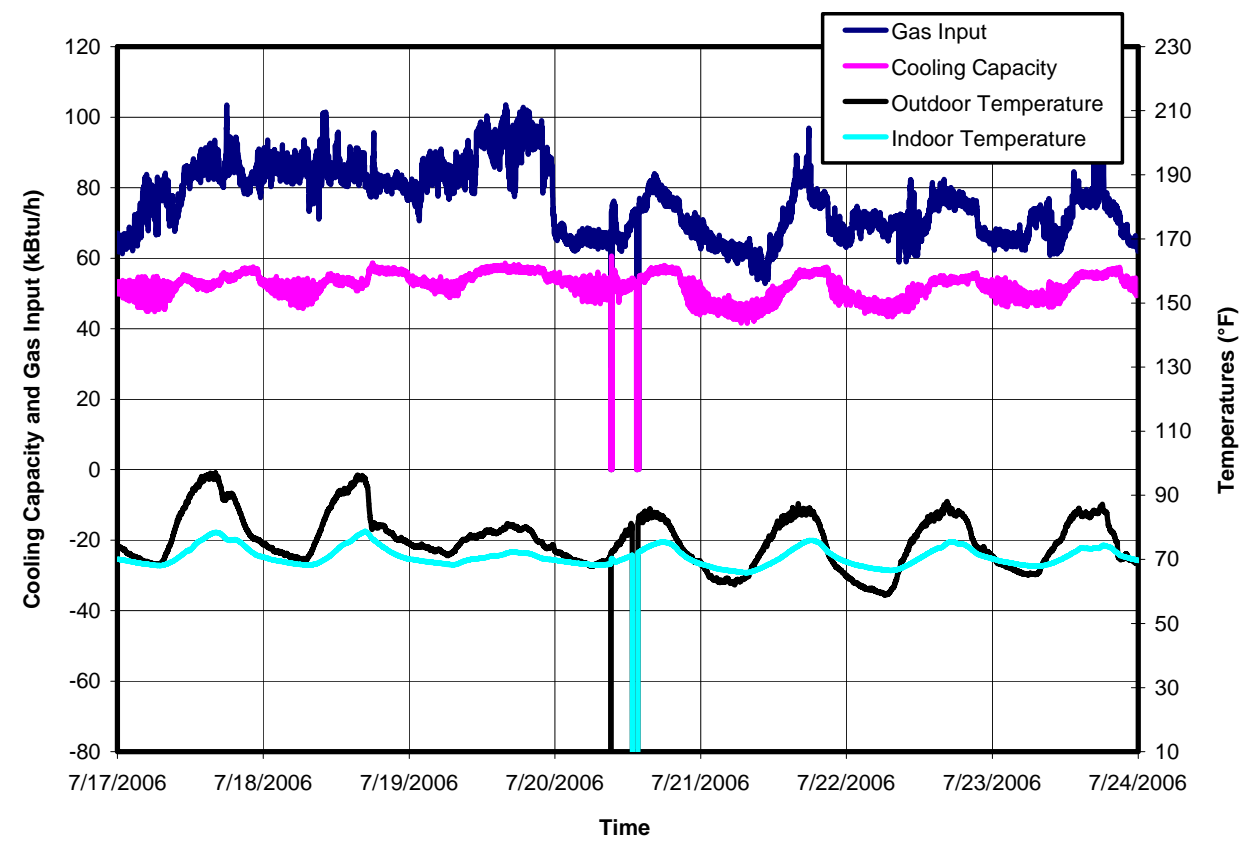

Figure 23. Cooling capacity of the aqua-ammonia chiller at ORNL, July 17 to $24,2006$. 


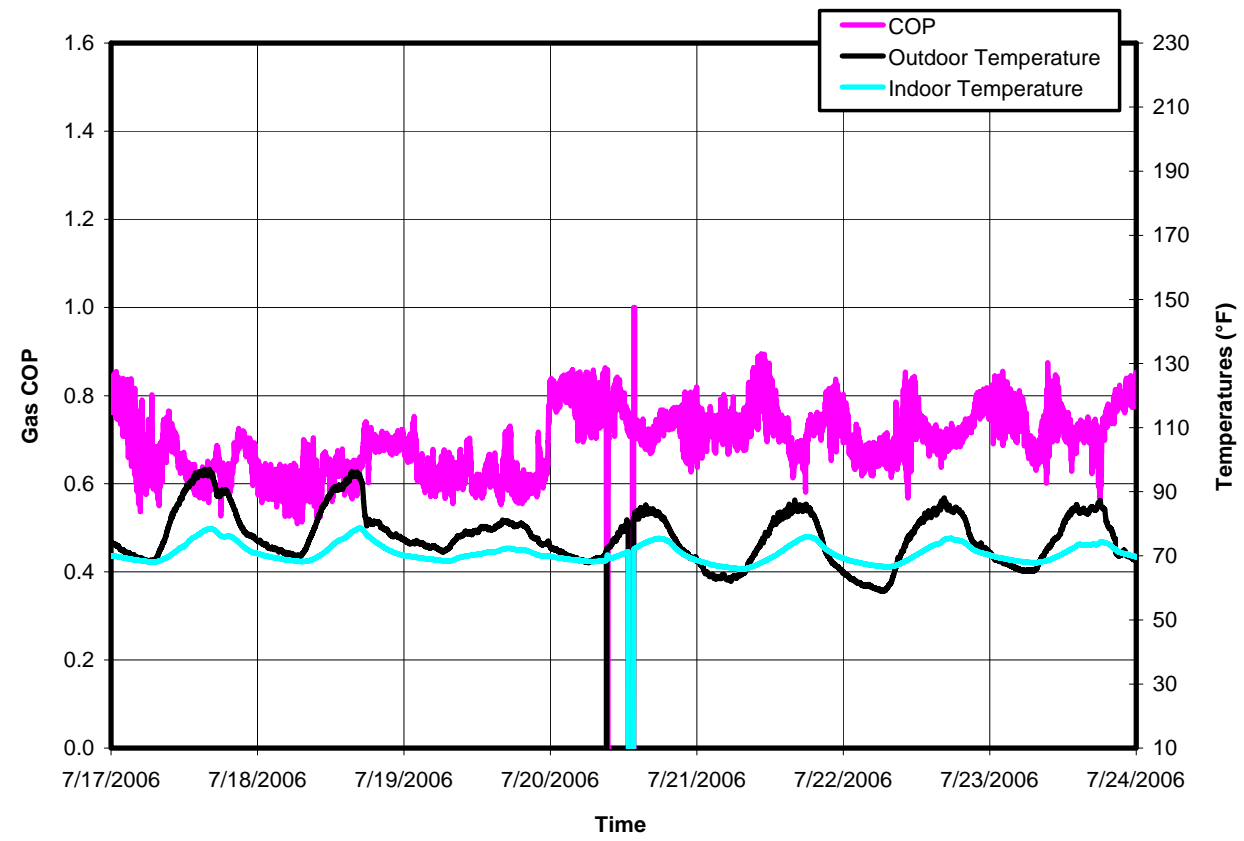

Figure 24. Gas COP of the aqua-ammonia chiller at ORNL, July 17 to $24,2006$.

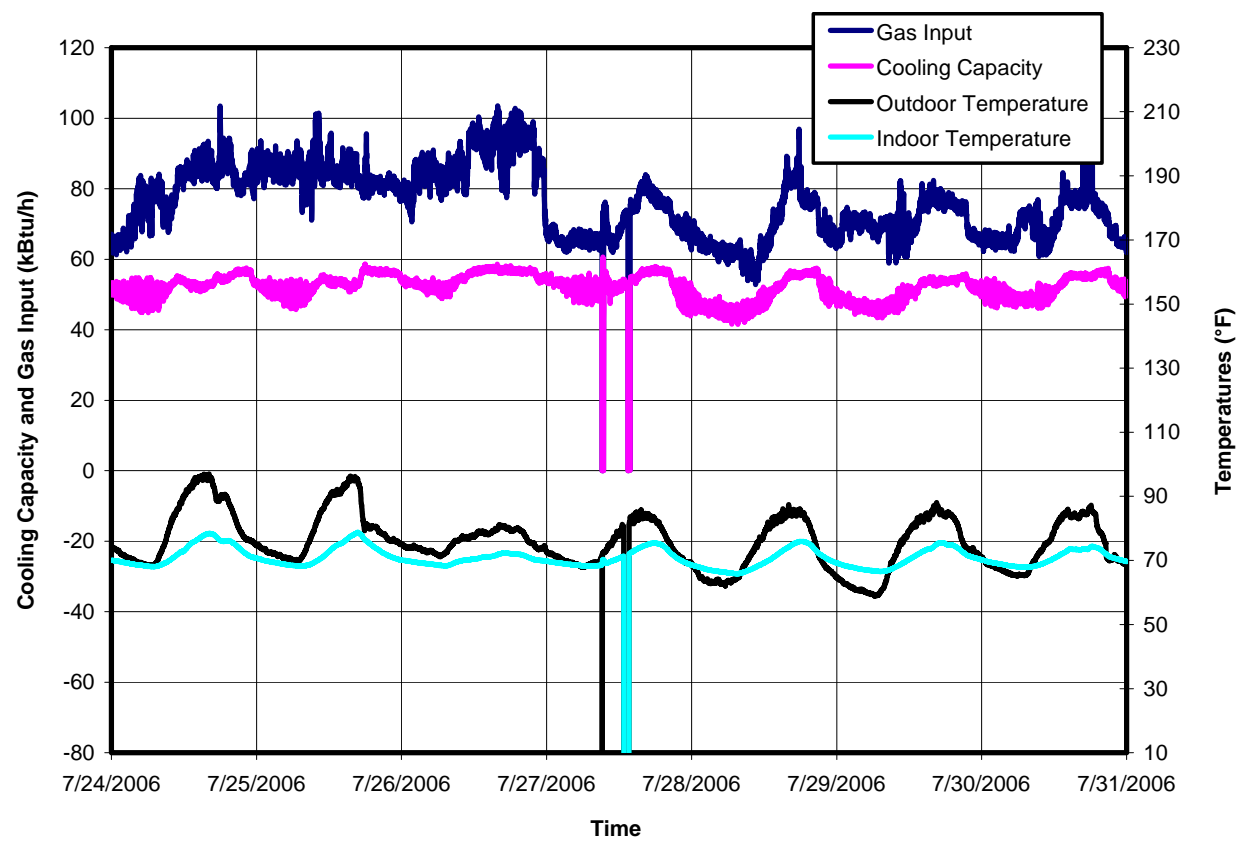

Figure 25. Cooling capacity of the aqua-ammonia chiller at ORNL, July 24 to 31, 2006. 


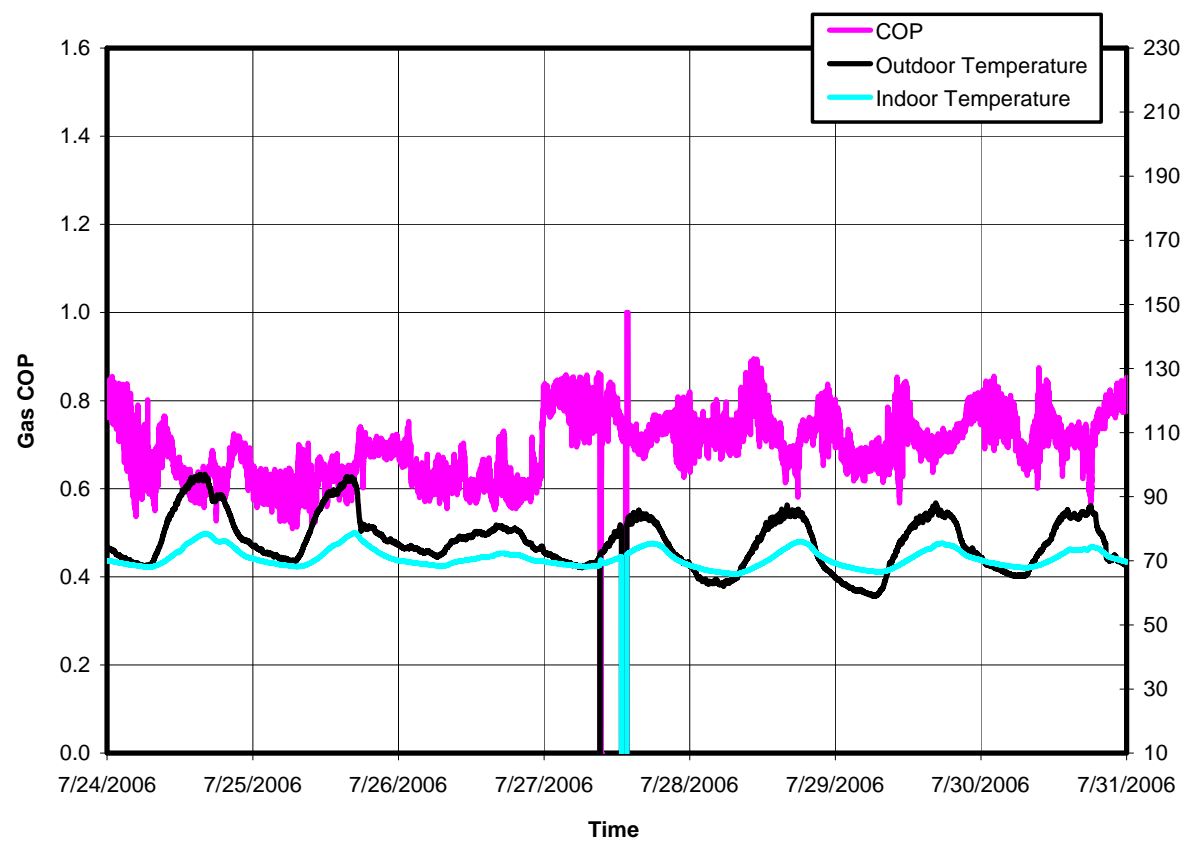

Figure 26. Gas COP of the aqua-ammonia chiller at ORNL, July 24 to 31, 2006.

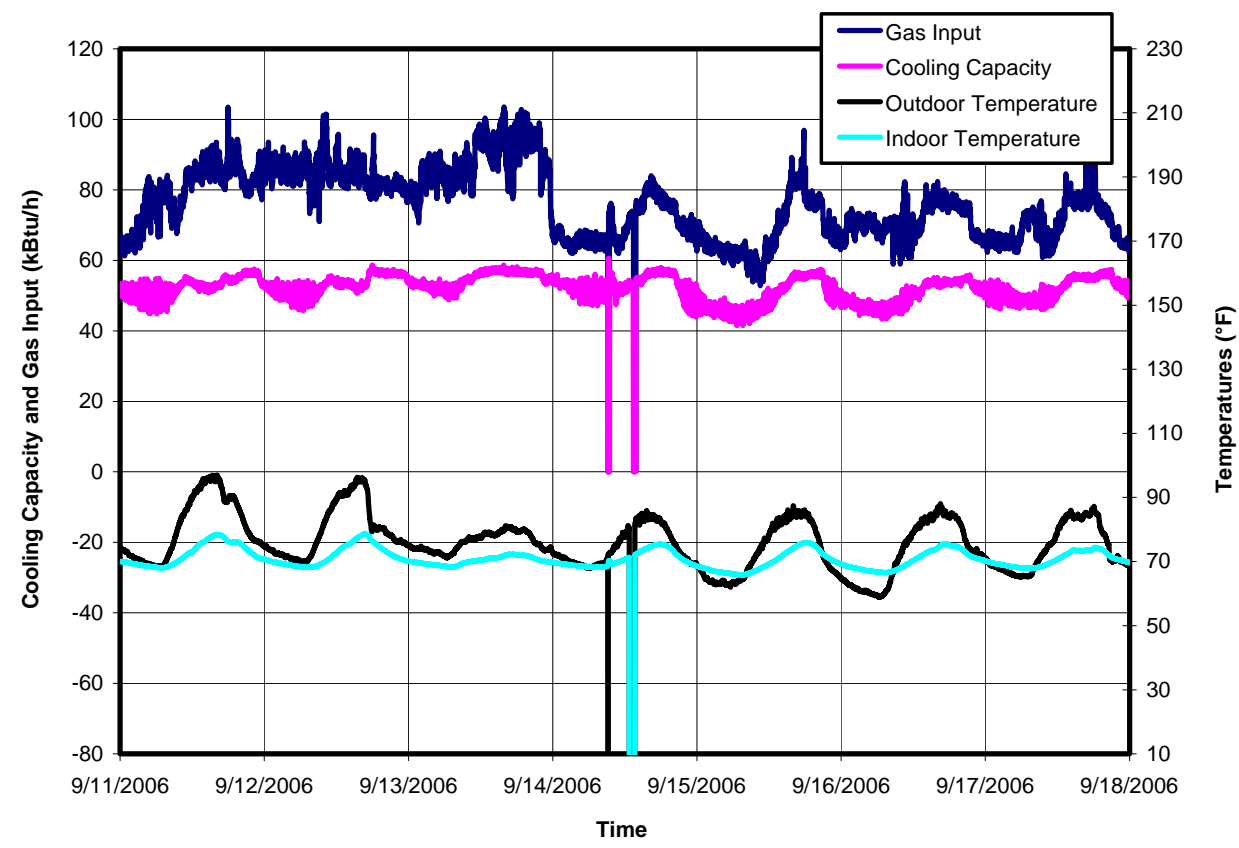

Figure 27. Cooling capacity of the aqua-ammonia chiller at ORNL, September 11 to 18, 2006 


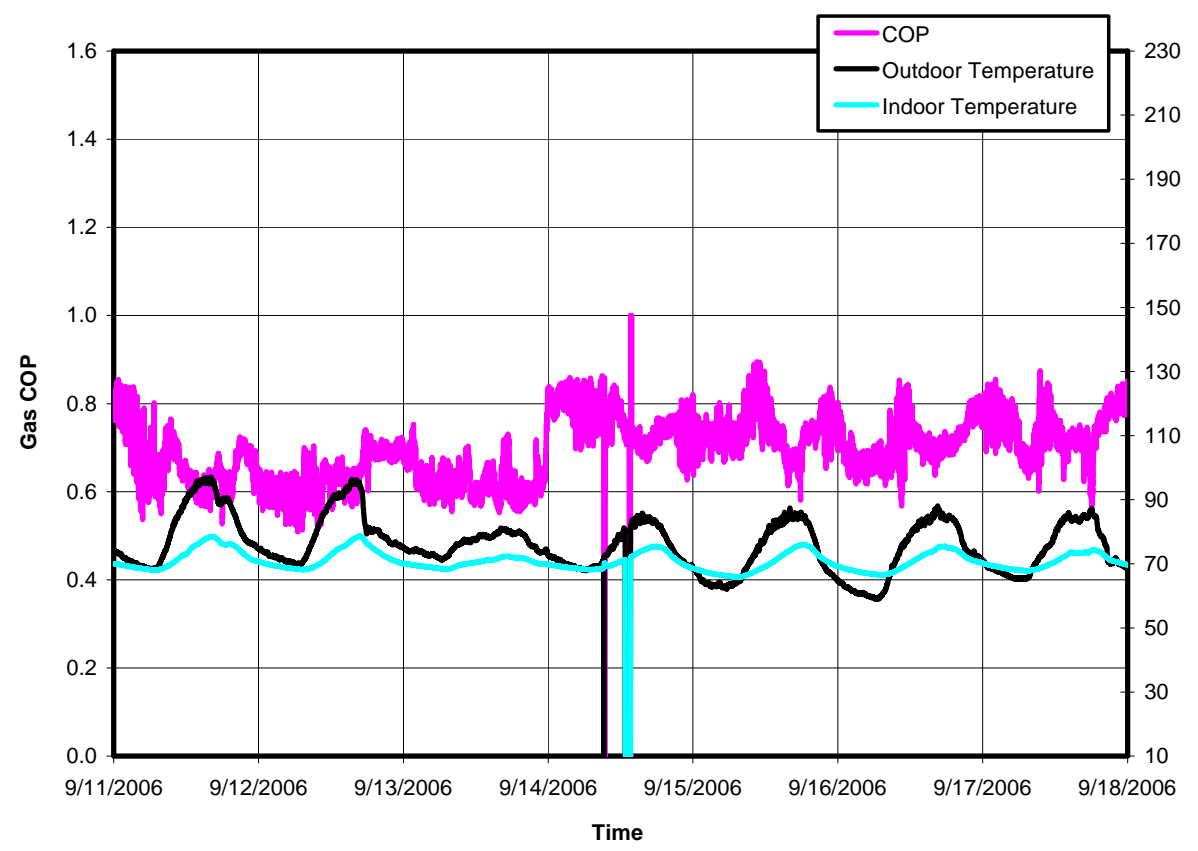

Figure 28. Gas COP of the aqua-ammonia chiller at ORNL, September 11 to 18,2006

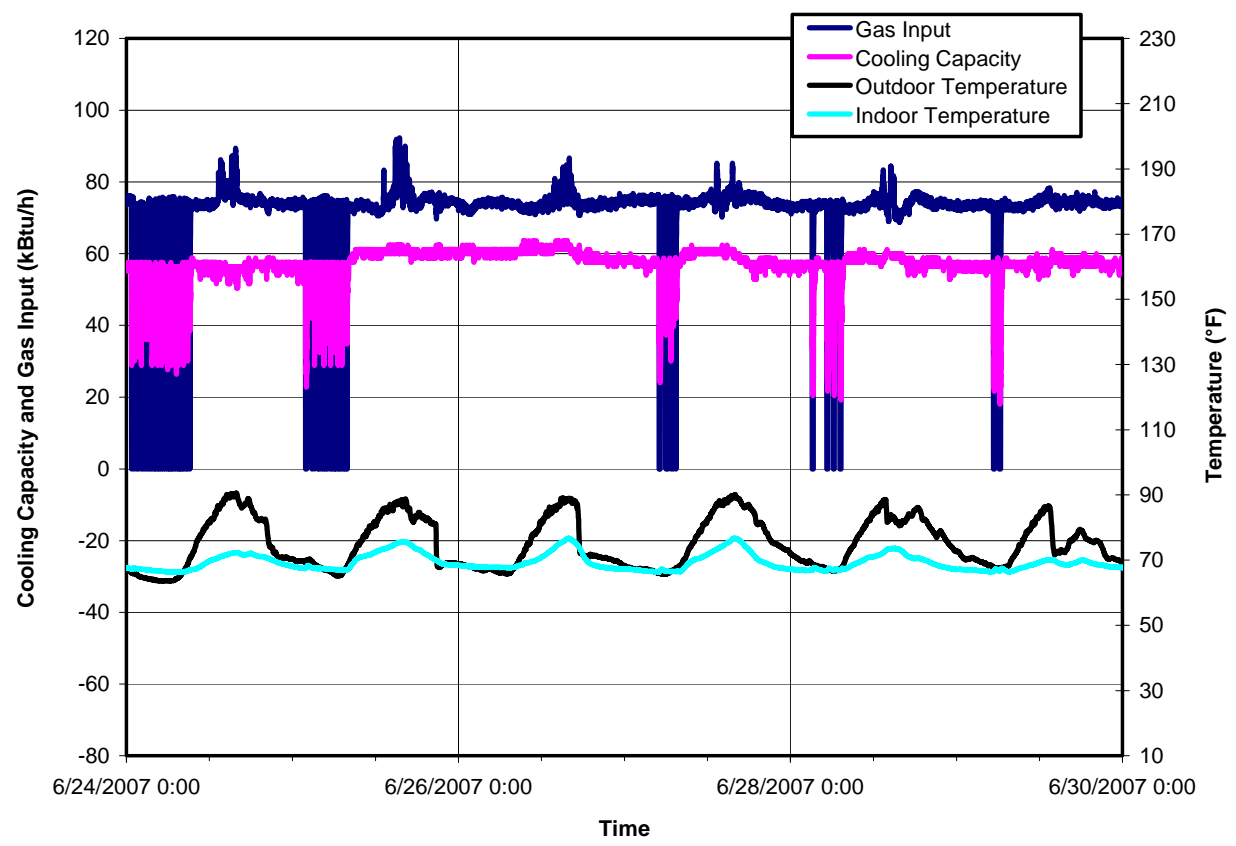

Figure 29. Cooling capacity of the aqua-ammonia chiller at ORNL, June 24 to 30, 2007. 


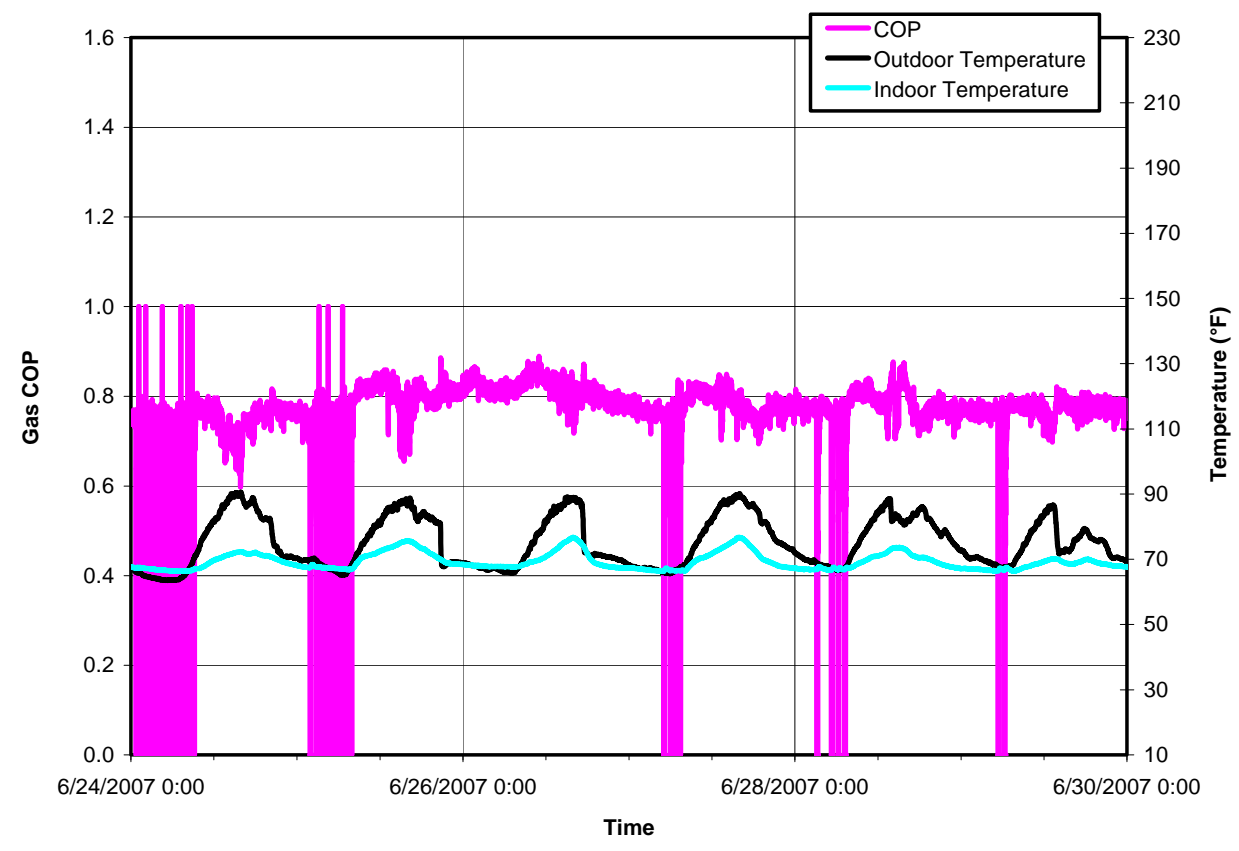

Figure 30. Gas COP of the aqua-ammonia chiller at ORNL, June 24 to $30,2007$.

\subsection{Field Experience, NAB Little Creek}

The installation of the third field test set-up was completed in November 2006. This installation has a chiller-link (two 5-ton chillers linked together to provide 10 tons of cooling). The chiller link controller developed under this project is being evaluated in this field test. Unfortunately, because of delays by the local gas company, we were unable to start commissioning/startup until April 2007. Because of this delay, we obtained only a couple of months of performance data, well short of our initial goal of two cooling seasons.

\section{Performance Test Results}

After initial commissioning and troubleshooting, the operation of the unit started in August 2007. Performance data were being collected at 1-minute intervals using ALC and Web Control. These field data were also available on a password-protected Web site for remote monitoring by our sponsor and Rocky Research. The field data were then converted to hourly data for bin analysis. The heating content of the natural gas (HHV) was also assumed to be constant at $1020 \mathrm{Btu} / \mathrm{scfm}$.

Figures 31-32 show examples of the performance of the chiller. Table 5 shows a bin analysis of the performance data at NAB Little Creek. The units are currently operating at the site.

Unfortunately, the expected load in the building does not seem to require 10 tons of capacity. This setup seems to be too large for the space, which results in high cycling losses and lower performance data, particularly at lower ambient conditions. In addition, the coolant pump could not provide a high enough water flow rate to both chillers (at least $12 \mathrm{gpm}$ ) because of a large restriction in the pipeline of Chiller 2. This circumstance also resulted in lower than expected performance results. 


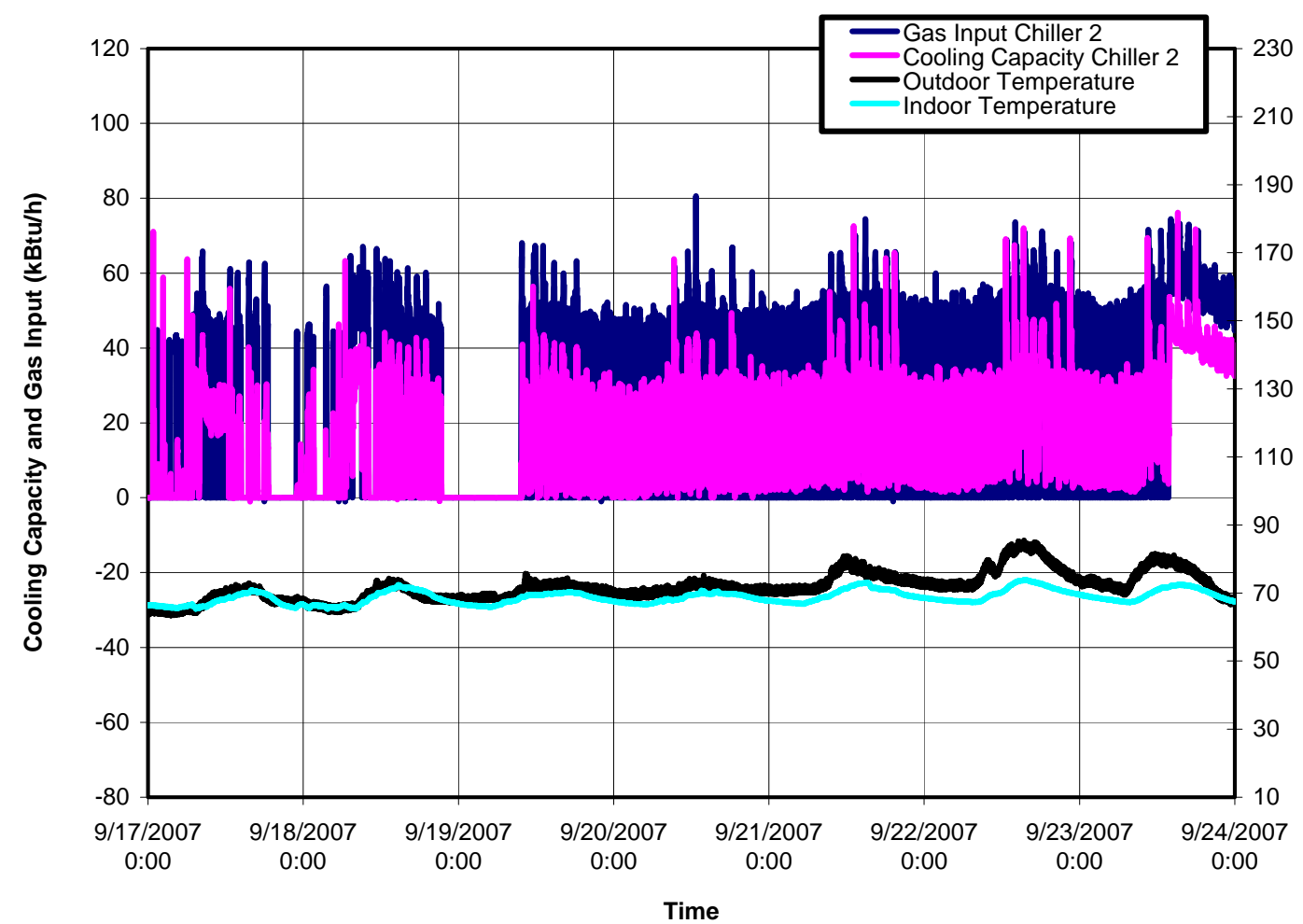

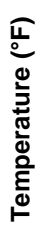

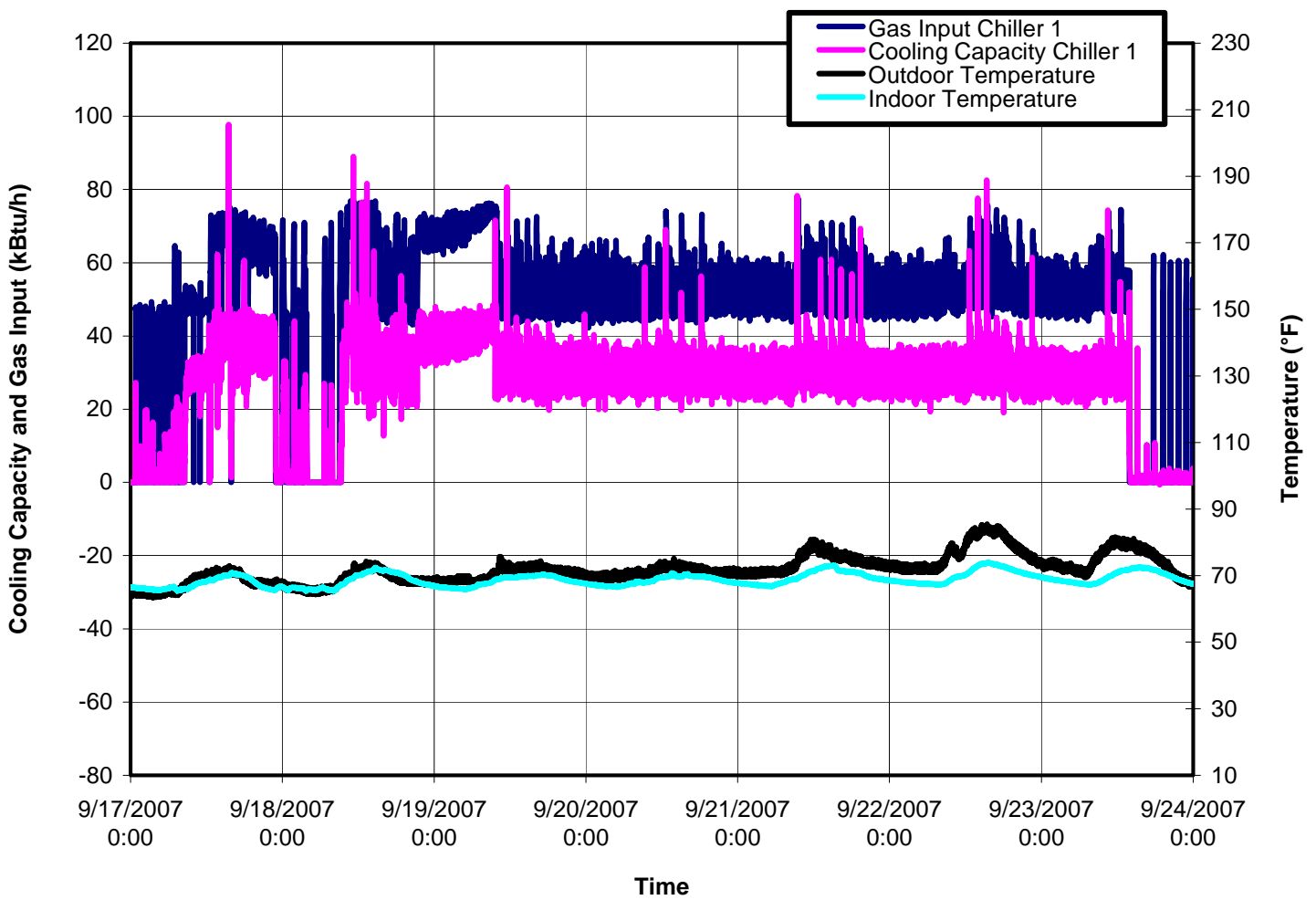

Figure 31. Cooling capacity of the aqua-ammonia chillers at NAB Little Creek, September 17 to $23,2007$. 


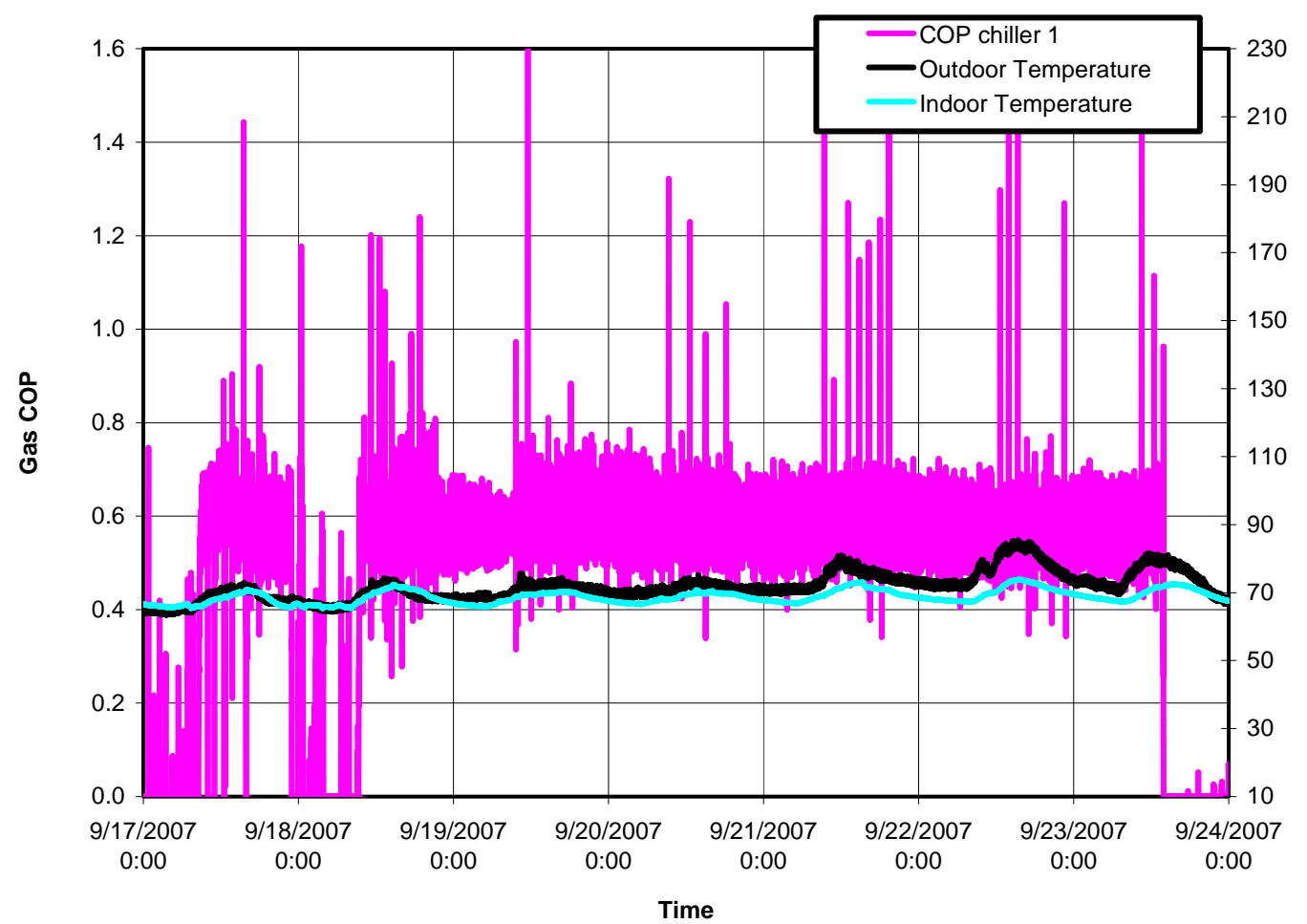

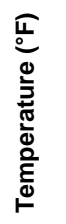

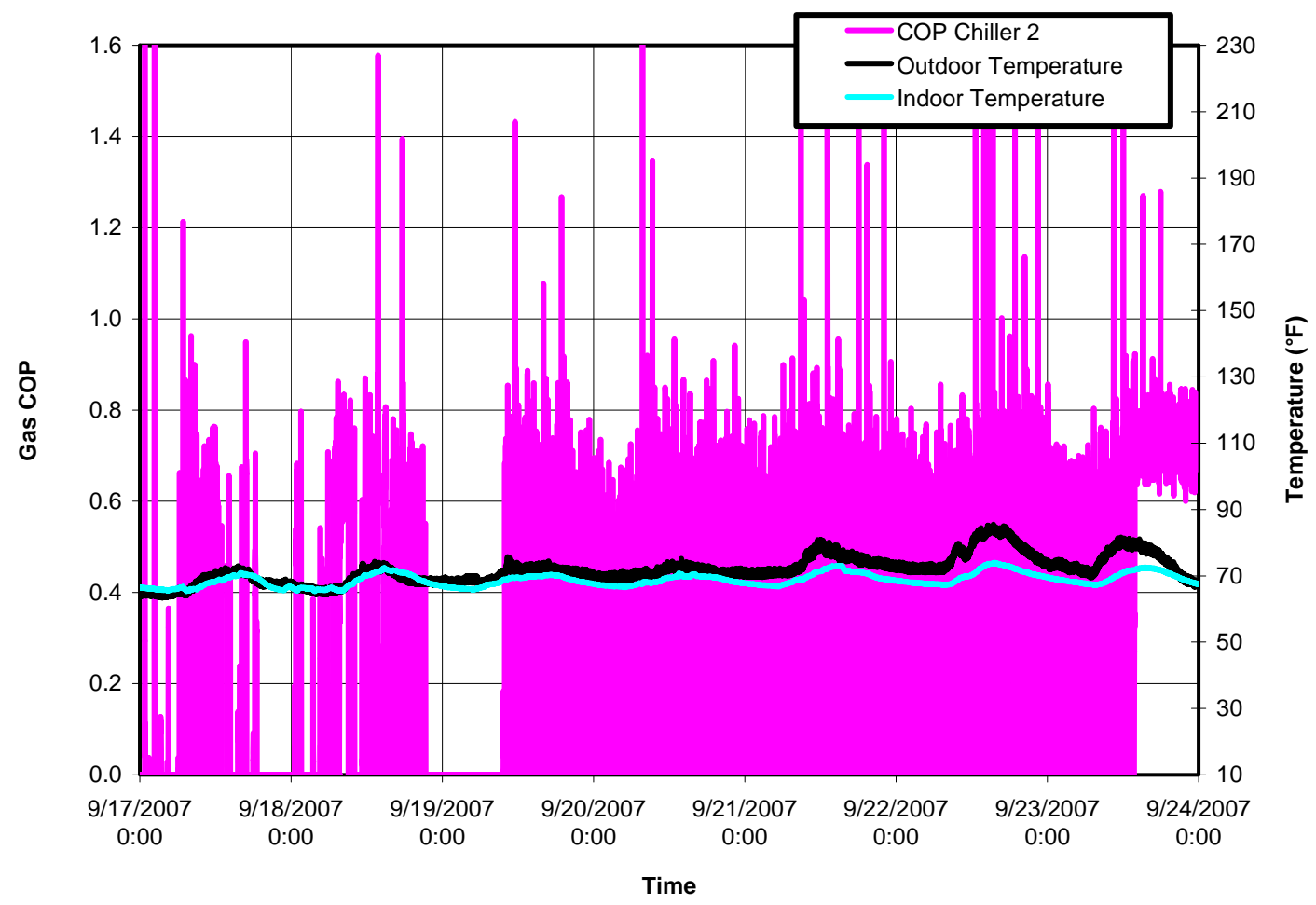

Figure 32. Gas COP of the aqua-ammonia chillers at NAB Little Creek, September 17 to 23, 2007. 


\section{Table 5. Performance Data at NAB Little Creek}

$\begin{array}{ccccccc}\begin{array}{c}\text { Bin Data } \\ \left({ }^{\circ} \mathrm{F}\right)\end{array} & \begin{array}{c}\text { COP } \\ \text { Chiller 1 }\end{array} & \begin{array}{c}\text { Cooling } \\ \text { Chiller 1 } \\ \text { (Btu/h) }\end{array} & \begin{array}{c}\text { Power } \\ \text { Chiller 1 } \\ \text { (kW) }\end{array} & \begin{array}{c}\text { COP } \\ \text { Chiller 2 }\end{array} & \begin{array}{c}\text { Cooling } \\ \text { Chiller 2 } \\ \text { (Btu/h) }\end{array} & \begin{array}{c}\text { Power } \\ \text { Chiller 2 } \\ \text { (kW) }\end{array} \\ 65-69 & 0.465 & 30,201 & 0.31 & 0.201 & 10,219 & 0.12 \\ 70-74 & 0.592 & 30,422 & 0.32 & 0.331 & 18,666 & 0.31 \\ 75-79 & 0.592 & 31,021 & 0.36 & 0.439 & 24,699 & 0.37 \\ 80-84 & 0.590 & 34,348 & 0.41 & 0.494 & 29,425 & 0.42\end{array}$

NAB Little Creek System Modifications. Minor adjustments were made to system charge inventories to optimize systems to loading and ambient conditions similar to the ones conducted at ORNL. The TXV design was improved by increasing the orifice size to eliminate possible noise similar to the one at ORNL. In addition, the two TXVs were each fitted with an updated diaphragm and bulb element. Subsequently, a few difficulties have arisen with the valve in one of these chillers, identified on the site as Chiller 2. The valve plunger shaft became bent, and owing to this malfunction the valve was replaced with a newly built one. The seat plunger o-ring then became displaced and was repaired.

The condenser fan motors, presently General Electric ECM2+, brushless dc type, failed in both units after extended outdoor exposure without operation at the site. These motors are shielded from the weather, but are of an open design, rather than of a weatherproof variety. Work is ongoing at Rocky Research to identify cost-effective alternatives for these motors on later units. The motors were replaced, and no further problems have arisen.

In the solution pump is a ball check valve, which includes a retainer cage. Two designs have been used for it, a three-piece sharp-edge design and a one-piece blunt-edge design. The tolerances of these are tight to the ball, and the newer blunt-edge design can seize the ball if particles enter the chamber. An instance of this occurred on chiller 2, and the cage was replaced with the three-piece design. The drawback to this design is that although the sharp edges prevent particle seizure, over a long period, they may be peened by the repeated movement of the hardened steel ball within, thereby reducing pump throughput over time. The time before pump throughput is affected is substantial so it is believed it was safe to exercise this option.

NAB Little Creek Control Changes. Initially, the controls were changed slightly to cause the chillers to pump glycol through all circuits in case of a cooling call when the water temperature does not indicate cooling demand. Similar modifications were conducted to the chiller setup at ORNL. This change is made to account for the case of warming water in the loop as air handlers begin to transfer heat; it allows for the pump to cease operation when the zones do not call for cooling and the water has been thoroughly cooled. Without the pump operating, the water temperature measurement, and in turn the cooling demand calculation, is undependable. Upon relaxation of all cooling calls, the chillers will cease operation upon arriving at the water temperature setpoint. This pumping method is the only sure way to secure dependable cooling during zone cycling, aside from permanent pump operation, which is undesirable when cooling cycles become infrequent.

Various small changes have been made to the control loop tuning optimization. Initially, the equipment was tested at Rocky Research with proportional-integral control in place. These 
perform well, but they have a decreased ability to adapt to other sites without rigorous re-tuning. For example, one particular set of coefficients works well on the Rocky Research test setup because of sustained loads with little change in cooling demand through the course of a typical day. At NAB Little Creek, however, the loads have been much more intermittent and rarely reach full two-unit capacity for sustained periods. The intermittent nature of the loads has prompted a few steps toward relaxation, and ultimately elimination, of the integrating portion of the control algorithm. Finally, the control has been configured with a decreased proportional band, which secures the full capacity of both chillers together at a reasonably small temperature deviation above the setpoint and minimal operation of only one chiller when the setpoint is met. While this arrangement allows some delivery temperature-setpoint offset, which is sub-optimal, it also eliminates overshoot and the oscillatory behavior that was being observed. The final result includes some unit cycling at certain demand levels, but this cannot be avoided. Specifically, this is the natural result of the fact that two chiller units operating at minimum capacity deliver more cooling than one unit at maximum capacity. Response filtering is in place and has been adjusted to the maximum presently available degree of short-cycle rejection, which is of great benefit in the absence of true integration but still cannot eliminate offset.

Other control changes have essentially involved debugging, i.e. securing desirable/ design performance from the controllers by eliminating errors in programming.

\section{Primary Fuel Utilization and Peak Demand Savings}

Building air-conditioning (cooling) is the single largest use of electricity driving increases in summer peak electric demand in much of the United States. Absorption chillers can provide overall peak load reduction and electric grid relief for the summer peak demand.

In comparing a 5-ton electric-driven vapor compression unit having an Energy Efficiency Ratio (EER) of 13 (site COP of 3.81) with an ammonia/water chiller (AWC) with a gas COP (at the site) of 0.66 (from ORNL laboratory data) at a $95^{\circ} \mathrm{F}$ rating condition in cooling mode, the resource COP must be used. To account for all the losses from the source to the site (end use), resource COP is a better efficiency metric to compare chillers with dissimilar energy streams. For grid-delivered electricity, the national average electricity loss reported by the Energy Information Administration for 2006 is approximately 68\%, based on the HHV of the primary fuel. Using the typical steady-state COP values given,

Absorption gas COP $=0.66$

Absorption electrical use $=0.8 \mathrm{~kW}$

Electrically driven chiller site COP $=3.81$

Electrically driven chiller resource COP $=3.81 * 0.32=1.22$

Absorption chiller resource COP (including electrical parasitics) $=0.60$

This shows an approximately 50\% lower resource COP for the absorption chiller; however, the absorption chiller provides peak load reduction during summer months. The electrically driven chiller requires $4.6 \mathrm{~kW}$ compared with $0.8 \mathrm{~kW}$ required by the AWC. This is a peak demand electricity savings of approximately $83 \%$.

This reduction in electrical generation capacity would also have other benefits, such as lower $\mathrm{NO}_{\mathrm{X}}$ and $\mathrm{CO}_{2}$ emissions and reduced water consumption required for central power plants. 


\section{Conclusions}

NFESC has sponsored ORNL to review, select, and evaluate advanced gas-fired 5-ton aquaammonia chiller technologies. From three potential manufacturers only one, Ambian, met our COP goal and our schedule.

Laboratory performance evaluations of two Ambian pre-commercial chillers were conducted at ARI conditions in the ORNL TAHP environmental chambers. Control strategies such as a variable-speed condenser fan, a modulating burner, and a TXV were effectively used to optimize the performance of these units. The capacity of these units was found to be approximately $56,500 \mathrm{Btu} / \mathrm{h}(4.7 \mathrm{RT})$ with a COP of 0.66 at the ARI $95^{\circ} \mathrm{F}$ condition. Within the accuracy range of the instrumentation, these results indicate that the Ambian units meet the desired performance levels for both capacity and COP. Compared with a comparable 13 EER electric heat pump, these absorption chillers used $83 \%$ less electrical energy at the $95^{\circ} \mathrm{F}$ ARI condition. This is a significant reduction in the peak demand and would result in considerable dollar savings by delaying/eliminating the need for future central station construction. This reduction in electrical generation capacity would also have other benefits, such as lower $\mathrm{NO}_{\mathrm{X}}$ and $\mathrm{CO}_{2}$ emissions and reduced water consumption required for central power plants.

Ambian pre-commercial units were selected for installation and field testing at three federal facilities. NFESC worked with ORNL to select these sites. Site selection criteria included building type, load, available backup (redundant) air-conditioning systems, ease of installation of the chiller and hydronic loop, project economics, and proximity to and interest of site personnel.

Two selected sites (ORNL and NSWC Corona) had a single 5-ton chiller unit each, and the third site (NAB Little Creek) had two 5-ton chillers linked together to provide 10 tons of cooling. A chiller link controller developed under this project was evaluated in the field test at Little Creek. Minor changes were made to the control scheme/strategies and to the sequencing to optimize the performance of these chillers in the field. As expected from pre-commercial units, some reliability/dependability issues were experienced during these field tests, which have been realized and easily mitigated on the next-generation units.

\section{Acknowledgments}

We would like to thank the NFESC, particularly Mr. Bruce Caldwell for sponsoring, contributing to, and supporting this work. In addition, we would like to thank our contacts at the two Navy facilities, Mr. Ernie Bryant of NAB Little Creek and Mr. Mark Graham of NSWC Corona for their participation and support at the test site.

\section{Bibliography}

Unitary Air-Conditioning and Air-Source Heat Pump Equipment, American National Standards Institute/Air-Conditioning and Refrigeration Institute Standard 210/240-94, 1998.

Methods of Testing for Rating Heat-Operated Unitary Air-Conditioning and Heat Pump Equipment, American National Standards Institute/American Society of Heating, Refrigerating and Air-Conditioning Engineers Standard 40-2002, 2002. 
Performance Testing and Rating of Gas-Fired, Air-Conditioning and Heat Pump Appliances, American National Standards Institute Standard Z21.40.4a-1998 and Compressed Gas Association Standard 2.94a-M98, 1998.

Standard Method for Temperature Measurement, American National Standards Institute/American Society of Heating, Refrigerating and Air-Conditioning Engineers Standard 41.1-1986 (RA 2006), 2006.

Instruments and Apparatus, Part 2, "Pressure Measurements,” ASME Power Test Code 19.21987 (Reaffirmed 2004), American Society of Mechanical Engineers, New York, 1987.

Standard Method for Pressure Measurement, American National Standards Institute/American Society of Heating, Refrigerating and Air-Conditioning Engineers Standard 41.3-1989, 1989.

ASME Power Test Code (PTC) 19.5-2004, Flow Measurement, 2004.

Standard Methods of Measurement of Flow of Liquids in Pipes Using Orifice Flowmeters, American Society of Heating, Refrigerating and Air-Conditioning Engineers Standard 41.81989, 1989.

Energy Information Administration 2006. Annual Energy Review 2006, DOE/EIA-0384(2006), posted June 2007, Washington, D.C. (http://www.eia.doe.gov/emeu/aer/contents.html)

High Density Housing, Mega-Developments: An Assessment of Arizona and Nevada Comparing Central Power to a Distributed Energy Approach, Blue Mountain Energy, Inc., Energy and Environmental Analysis, Inc., July 2006. 